\title{
Legal but lethal: functional protein aggregation at the verge of toxicity
}

\author{
Angelika Falsone and S. Fabio Falsone* \\ Institute of Pharmaceutical Sciences, University of Graz, Graz, Austria
}

\section{Edited by:}

Rosanna Parlato, Ulm University, Germany

Reviewed by:

Daniel Kaganovich, Hebrew

University of Jerusalem, Israel,

Israel

Robert Weissert, University of

Regensburg, Germany

${ }^{*}$ Correspondence:

S. Fabio Falsone, Institute of

Pharmaceutical Sciences,

University of Graz, Schubertstr. 1, 8010 Graz, Austria

e-mail: fabio.falsone@uni-graz.at
Many neurodegenerative disorders are linked to irreversible protein aggregation, a process that usually comes along with toxicity and serious cellular damage. However, it is emerging that protein aggregation can also serve for physiological purposes, as impressively shown for prions. While the aggregation of this protein family was initially considered exclusively toxic in mammalians organisms, it is now almost clear that many other proteins adopt prion-like attributes to rationally polymerize into higher order complexes with organized physiologic roles. This implies that cells can tolerate at least in some measure the accumulation of inherently dangerous protein aggregates for functional profit. This review summarizes currently known strategies that living organisms adopt to preserve beneficial aggregation, and to prevent the catastrophic accumulation of toxic aggregates that frequently accompany neurodegeneration.

Keywords: amyloids, prions, proteotoxicity, neurodegenerative diseases, proteostasis regulators

\section{INTRODUCTION}

Low structural complexity is at the basis of highly diversified molecular recognition, whereby one flexible protein region can bind to various heterogeneous ligands by conformational adaptation. Proteins can functionally benefit from binding promiscuity for key regulatory processes such as signal transduction, transcription, RNA processing and translation. Proteins situated on intersecting hubs of different pathways can undergo multifunctional interactions, functioning as molecular switches by means of conformational variability. However, the benefits of conformational freedom come along with the menace of protein misfolding and multifunctional failure. Although each living organism invests conspicuous amounts of energy for the rescue or elimination of misfolded polypeptides, a possible inability of the cell to cope with misfolded polypeptides inevitably leads to a massive functional destabilization, whereby proteins can either lose their original function (loss-of-function), or they acquire an improper, and therefore mostly lethal function (gain-of-function), eventually aggregating after the complete collapse of folding and clearance pathways.

The central nervous system (CNS) is particularly susceptible to protein misfolding, but the reasons of such selective neuronal vulnerability are still elusive (Saxena and Caroni, 2011). Although healthy adult neurons can manage proteostasis by standard folding and degradation routines (see Section Molecular catchers

\footnotetext{
Abbreviations: CNS, central nervous system; PD, Parkinson Disease; AD, Alzheimer Disease; ALS, amyotrophic lateral sclerosis; FTD, frontotemporal dementia; HD, Huntington Disease; aSyn, alpha-synuclein; Abeta, betaamyloid; prp, major prion protein; htt, huntingtin; PLR, prion-like region; SG, stress granules; hsp, heat shock protein; UPS, ubiquitin-proteasome system; CMA, chaperone-mediated autophagy; MA, macroautophagy; GAG, glycosaminoglycan; HSPG, heparan suphate proteoglycans.
}

in the amyloid rye: heat shock proteins and proteolytic pathways), macroscopic protein misfolding manifestations prevail with senescence, as attested by the occurrence of ageing-associated neurodegenerative disorders such as Parkinson Disease (PD), Alzheimer Disease (AD), spongiphorm encephalopathies, or amyotrophic lateral sclerosis (ALS), all of them displaying unsoluble protein inclusions as a signature.

\section{AMYLOID AGGREGATION STRUCTURAL PROPERTIES OF AMYLOIDS}

Irrespectively of the protein structure and the exact anatomic localization, one type of proteinaceous inclusions appearing in the CNS features some unifying histologic and biophysical hallmarks classified under the term "amyloid", consisting of (A) a fibrous, non-branched morphology, (B) the ability to alter the spectral properties of the dyes Congo red and thioflavin $\mathrm{T}$, and (C) $\mathrm{X}$-ray diffraction patterns typical of cross-beta structure. The term was coined by German pathologist Rudolf Virchow during the characterization of masses in human brains described as "corpora amylacea". Virchow perceived the relationship between amyloids and disease, when he addressed the problem of "amyloid degeneration" (Virchow, 1855). Today, it is well established that the appearance of amyloids is associated with a chronic tissue degeneration of the brain, and although not restricted to this organ, our current understanding of misfolding diseases is invariably linked to amyloid-associated neurological brain disorders (For a detailed list of known amyloid diseases, we refer to the classification of the International Society of Amyloidosis Sipe et al., 2014).

Amyloid aggregation is stereotypically linked to conformational flexibility, which allows for structurally diverse polypeptides to fold from a native into an alternative structure of the same 
chemical composition, but with high beta-sheet content, a remarkable resistance against proteolytic and denaturing agents, and the ability to self-associate into fibers of typical cross-beta structure (Eisenberg and Jucker, 2012). The pathway of this association is dynamically variegated, highly perturbable, and sensitive to a repertoire of factors such as genetic mutations, small ligands, changes of the physico-chemical environment, or post-translational side chain modifications (Eichner and Radford, 2011). The resulting heterogeneous multiplicity of conformational intermediates differing in size, shape and stability poses an obstacle in isolating and unambiguously categorizing amyloid aggregates, especially these conformers among them which are believed to be proteotoxic (Eisenberg and Jucker, 2012), and which likely accumulate in low amounts somewhere between native polypeptide and mature amyloid. Improved biophysical techniques can in part overcome these limitations, and they are beginning to provide useful structural insights of amyloid folding intermediates. By combining rapid fluorescence techniques with NMR spectroscopy, Sarkar et al. measured conformational fluctuations of a short-lived, low-abundance ADassociated beta-amyloid (Abeta) oligomer (Sarkar et al., 2014). They could pinpoint the dynamic structure of this oligomer to a patchwork of amino acid segments which fold locally before the transition into highly ordered amyloid filaments. Likewise, Röthlein et al. employed time resolved fluorescence and computational calculations to obtain structural views of an extremely unstable huntingtin (htt) amyloid filament (Röthlein et al., 2014).

\section{MOLECULAR PATHWAYS OF AMYLOID PROPAGATION}

Amyloid folding has been coupled early to prion diseases (Prusiner et al., 1983), a type of devastating neurodegenerative disorders that are transmitted by direct and self-sustained intercellular propagation of toxic agents, which constitutes an outstanding and devastating strategy to bypass genetic routes of infection. While the infectious prion particle known as $\mathrm{PrP}^{\mathrm{Sc}}$ is typically amyloid (Prusiner et al., 1983), the cellular conformer $\mathrm{PrP}^{\mathrm{c}}$ is a non-amyloid, non-infectious globular protein of still undefined function. This striking difference led to suppose that prion proteins must access an amyloid state to acquire transmissible properties.

A growing amount of studies suggests that this type of cellto-cell transmission is apparently common to amyloids, as it has been observed also for other amyloidogenic proteins with well-known implication in neurodegenerative diseases (Table 1), suggesting that the amyloid fold is a structural prerequisite of cell-to-cell propagation (Eisenberg and Jucker, 2012). Indeed, it was discovered, that amyloidogenic proteins such as alphaSynunclein (aSyn), tau, or Abeta can also propagate between cells, and that these transmissible particles share structural properties closely similar to those of the archetypic infectious particle $\operatorname{PrP}^{\mathrm{sc}}$ : they have a predominant beta-sheet structure, a remarkable resistance against proteolytic and denaturing agents, and a self-templating ability (Prusiner et al., 1983; Luk et al., 2012; Iba et al., 2013; Sanders et al., 2014; Stöhr et al., 2014; Watts et al., 2014). Similar rearrangements are likely to occur for endogenous tau in mice brains upon the stereotactic delivery of toxic tau seeds, which is sufficient to initiate spreading of AD-like neurofibrillary tangles along a spatially defined trajectory (Iba et al., 2013). In close analogy, the injection of aSyn seeds into brains of healthy mice triggers the self-perpetuating polymerization of endogenous aSyn and the development of clinical symptoms of PD (Luk et al., 2012). In both cases, the sequential diffusion of proteotoxicity along interconnected brain regions substantiates the theory of a staged evolution of PD and AD (Braak et al., 2006). With respect to original prions, all these proteins have thus been attributed "prion-like" or "prionoid" propagation properties. However, complicating a pathologic interpretation is the occurrence of different conformationally variable toxic species from the same protein, with separate propagation behavior and distinct phenotypic manifestations of the same condition. Sanders et al. demonstrated that tau, the signature protein of tauopathies, forms biochemically and morphologically distinct oligomers accounting for different disease phenotypes, with $\mathrm{AD}$ inclusions showing the most homogenous composition (Sanders et al., 2014). Similar has been shown for Abeta, the major component of $\mathrm{AD}$ amyloid plaques. Different patient-derived as well as synthetic species of Abeta display an individual transmission behavior, accumulation pattern, aggregate morphology, and chemical stability (Stöhr et al., 2014; Watts et al., 2014). Bousset et al., also reported of two differently toxic aSyn conformers with separate propagation properties (Bousset et al., 2013). Additional complexity rises from the ability of particular amyloid aggregates to act as cross-nucleation seeds for other structurally unrelated proteins. Alpha-Synunclein (aSyn), the major constituent of PD associated Lewy Inclusions, can initiate the deposition of tau in primary neurons and transgenic mice (Guo et al., 2013), while TDP-43 amyloids can seed for Abeta fibril growth (Fang et al., 2014), which might contribute to co-morbidities observed for some types of amyloid pathologies.

\section{Exosomes}

We have only a slight clue on the mechanisms of intercellular prion spreading. Recent investigations point to exosomes (Table 1), a type of membrane-enclosed vesicle sized 30-100 nm, with the ability of transporting a remarkably diverse cargo ranging from active proteins to different RNA particles for cellular exchange (Kowal et al., 2014). Exosomes have been associated with prion transmission since the isolation of $\mathrm{PrP}^{\mathrm{sc}}$ from exosome preparations after cellular infection with sheep prions (Fevrier et al., 2004), and PrP-loaded exosomes could be successively isolated from brain fluids of infected animals (Vella et al., 2008).

It seems that the exosome-mediated secretion of amyloidassociated proteins is an organized process, as it can be triggered by determinate signaling events, such as calcium release (Emmanouilidou et al., 2010), or platelet activation (Robertson et al., 2006). Of fundamental importance, $\operatorname{PrP}^{s c}$ or aSyn oligomers isolated from exosomes retain full toxicity, suggesting that these organelles can indeed serve as infectious vehicles (Fevrier et al., 2004; Vella et al., 2007; Danzer et al., 2012). This leads to hypothesize that the exosome-mediated release 
Table 1 | Summary of representative proteins handled within this review, with respect to pathology, and prion/prion-like properties.

\begin{tabular}{|c|c|c|c|c|c|}
\hline $\begin{array}{l}\text { Protein } \\
\text { name }\end{array}$ & $\begin{array}{c}\text { Most relevant } \\
\text { associated diseases }\end{array}$ & $\begin{array}{c}\text { Amyloid } \\
\text { polymerization }\end{array}$ & $\begin{array}{l}\text { Cell-to-cell } \\
\text { transmission }\end{array}$ & $\begin{array}{l}\text { Exosomal } \\
\text { secretion }\end{array}$ & $\begin{array}{l}\text { HSPG } \\
\text { binding }\end{array}$ \\
\hline aSyn & $\begin{array}{l}\text { PD; } \\
\text { Dementia with Lewy } \\
\text { Bodies }\end{array}$ & $Y_{e s}^{a}$ & Yes (Luk et al., 2012) & $\begin{array}{l}\text { Yes (Alvarez- } \\
\text { Erviti et al., } \\
2011 \text { ) }\end{array}$ & $\begin{array}{l}\text { Yes (Holmes et al., } \\
\text { 2013) }\end{array}$ \\
\hline Abeta & $A D$ & $Y_{e s}^{a}$ & $\begin{array}{l}\text { Yes (Stöhr et al., } \\
\text { 2014; Watts et al., } \\
\text { 2014) }\end{array}$ & $\begin{array}{l}\text { Yes (Rajendran } \\
\text { et al., 2006) }\end{array}$ & $\begin{array}{l}\text { Yes (Holmes et al., } \\
\text { 2013) }\end{array}$ \\
\hline $\operatorname{PrP}$ & $\begin{array}{l}\text { spongiphorm } \\
\text { encephalopathies }\end{array}$ & $Y_{e s}^{a}$ & Yes $^{a}$ & $\begin{array}{l}\text { Yes (Fevrier et al., } \\
\text { 2004) }\end{array}$ & $\begin{array}{l}\text { Yes (Horonchik et al., } \\
\text { 2005) }\end{array}$ \\
\hline tau & tauopathies & $\begin{array}{l}\text { Yes }^{b} \text { (Iba et al., 2013; } \\
\text { Morozova et al., 2013) }\end{array}$ & Yes (Iba et al., 2013) & $\begin{array}{l}\text { Yes (Saman } \\
\text { et al., 2012) }\end{array}$ & $\begin{array}{l}\text { Yes (Holmes et al., } \\
\text { 2013) }\end{array}$ \\
\hline FUS & ALS; FTD & $\begin{array}{l}\text { Yes (Schwartz et al., } \\
2013 \text { (in the presence } \\
\text { of RNA); Nomura et al., } \\
2014 \text { (G156E variant); } \\
\text { Han et al., 2012; Kato } \\
\text { et al., 2012; Kwon } \\
\text { et al., } 2013 \text { (FUS low } \\
\text { complexity region)). }\end{array}$ & $?$ & $?$ & $?$ \\
\hline TDP-43 & ALS; FTD & $\begin{array}{l}\text { Yes (Guo et al., 2011; } \\
\text { Fang et al., } 2014 \text { (A315T } \\
\text { variant); Chen et al., } \\
\text { 2010; Furukawa et al., } \\
2011 \text { (G294A variant)) }\end{array}$ & $\begin{array}{l}\text { Yes (Nonaka et al., } \\
\text { 2013) }\end{array}$ & $\begin{array}{l}\text { Probable } \\
\text { (Nonaka et al., } \\
\text { 2013) }\end{array}$ & $?$ \\
\hline $\mathrm{Cu} / \mathrm{Zn}$ & ALS & Yes (DiDonato et al., & Yes (Münch et al., & Yes (Grad et al., & Yes (Inoue et al., \\
\hline SOD & & $\begin{array}{l}\text { 2003(ALS-associated } \\
\text { mutants)) }\end{array}$ & $\begin{array}{l}\text { 2011; Grad et al., } \\
\text { 2014) }\end{array}$ & 2014) & 1991) \\
\hline hnRNPA & $\begin{array}{l}\text { multiple system } \\
\text { proteinopathy }\end{array}$ & $\begin{array}{l}\text { Yes (Kato et al., 2012; } \\
\text { Kim et al., 2013) }\end{array}$ & $\begin{array}{l}\text { Yes (Kato et al., 2012; } \\
\text { Kim et al., 2013) }\end{array}$ & $?$ & $?$ \\
\hline TIA-1 & $\begin{array}{l}\text { Welander distal } \\
\text { myopathy }\end{array}$ & $\begin{array}{l}\text { Yes (Furukawa et al., } \\
\text { 2009; Li et al., 2014) }\end{array}$ & Yes (Li et al., 2014) & $?$ & $?$ \\
\hline $\begin{array}{l}\text { polyQ- } \\
\text { huntingtin } \\
\text { (htt) }\end{array}$ & HD & $\begin{array}{l}\text { Yes (Lotz et al., 2010; } \\
\text { Falsone et al., 2012) }\end{array}$ & $?^{\mathrm{C}}$ & $?$ & $\begin{array}{l}\text { No (Holmes et al., } \\
\text { 2013) }\end{array}$ \\
\hline CPEB $^{d}$ & - & $\begin{array}{l}\text { Yes (Raveendra et al., } \\
\text { 2013) }\end{array}$ & Yes (Si et al., 2003) & $?$ & $?$ \\
\hline Sup35e & - & $Y_{e s}^{a}$ & $Y_{e s}^{a}$ & $?$ & - \\
\hline
\end{tabular}

${ }^{a}$ prototypic representatives

${ }^{b}$ in the presence of heparin

cprion-like propagation with synthetic polyQ fibrils (Ren et al., 2009)

d from Aplysia californica

efrom Saccharomyces cerevisiae.

of noxious agents might originally represent a rational strategy to relieve cells from toxicity. Such a hypothesis is supported by studies showing that when the intracellular clearance of aSyn is compromised, an elevated deployment of exosomes carrying this protein as a cargo becomes observable (AlvarezErviti et al., 2011; Danzer et al., 2012). With this respect, an intact exosomal secretion pathway appears essential for neuroprotection. Upon the manipulation of PARK9/ATP13A2, a component of the exosome biogenesis machinery, cells can less efficiently counteract intraneuronal aSyn toxicity. Accordingly, surviving neurons from PD patients display increased levels of PARK9/ATP13A2 (Kong et al., 2014), whereas affected neurons show decreased levels (Murphy et al., 2013). In a purely speculative way, deregulated cells that are no longer able to efficiently handle the clearance of proteotoxic species might pass over their own toxic burden to functioning cells for disposal.

Interestingly, in vitro generated aSyn, tau, Abeta, PrP or polyQ aggregates can be efficiently internalized when directly applied to growing cells or animals, apparently without an exosomal delivery (Horonchik et al., 2005; Ren et al., 2009; Luk et al., 2012; Holmes et al., 2013; Iba et al., 2013; Aulić et al., 2014; Volpicelli-Daley et al., 2014), suggesting the existence of additional pathways of transmission. As shown for ALS-associated $\mathrm{Cu} / \mathrm{Zn}$-superoxide dismutase (SOD), parallel exosome dependent and independent mechanisms have been 
postulated, whereby an active exosome-associated secretion can be backed by a passive, carrier-free diffusion of toxic particles, probably upon their release from necrotizing cells (Grad et al., 2014).

\section{Proteoglycans}

A recent study identifies heparan sulphate proteoglycans (HSPGs) as further key players of intercellular transmission (Holmes et al., 2013; Table 1). HSPGs are a class of membrane proteins conjugated to the heavily sulphated glycosaminoglycan (GAG) heparan sulphate, which is a constituent of the extracellular matrix (Xu and Esko, 2014). Although HSPGs are traditionally coupled to cell attraction and migration, a pathologic link with amyloid diseases has been postulated ever since the identification of GAGs in various types of amyloid deposits from affected brains (Snow et al., 1988, 1990; Spillantini et al., 1999).

HSPGs are direct targets of pathologic PrP, aSyn, Abeta and tau (Horonchik et al., 2005; Holmes et al., 2013). All of them become actively internalized after HSPG binding, consequently propagate within neuronal cells, and sustain the development of a pathologic condition. The physico-chemical integrity of the GAG-chains appears essential for binding, as the subsequent internalization becomes affected upon chemical or genetic alteration of the GAG residues (Holmes et al., 2013). Indeed, GAGs were attributed amyloid modifying properties in vitro depending on the size (Vieira et al., 2014) and charge (Lawson et al., 2010) of the GAG chain. Given that the proteoglycan expression and GAG-composition are cell-specific and vary with brain development and senescence (Rykova et al., 2011), it can be speculated that ageing-related changes in cell-surface proteoglycan patterns will influence HSPG-mediated prion-like propagation.

HSPGs might represent a converging hub for exosomedependent and independent prion propagation, owing to some potential overlaps between both pathways. HSPGs can regulate also exosome internalization (Christianson et al., 2013), and GAG modifications affect both amyloid internalization and exosomal uptake (Christianson et al., 2013; Holmes et al., 2013). Both processes further initiate macropinocytosis, a mechanism whereby macromolecules are taken up by actin-membrane ruffles (Fitzner et al., 2011; Holmes et al., 2013). Finally, exosomes and proteopathic seeds activate identical neuroinflammatory pathways (Thellung et al., 2007; Tomasi, 2010; Christianson et al., 2013). Collectively, these considerations suggest an exosome/HSPG unifying route for prion entry.

\section{AMYLOID FUNCTION PHYSIOLOGIC SIGNIFICANCE OF AMYLOID POLYMERIZATION}

While in humans the concept of amyloid has been traditionally interpreted in terms of lethality, observations from various evolutionary distinct organisms strongly support a role that extends well beyond toxicity. In prokaryotes, cell-surface amyloid polymerization is quite diffuse (Dueholm et al., 2013), and the biogenesis of curli filaments from enterobacteria is an example of how unicellular organisms use amyloidogenesis for physiological processes such as biofilm formation, host adhesion, and cellular clustering. CsgA protein, the principal component of curli in E. coli, polymerizes into amyloids after the secretion across the outer membrane. In vivo, this process is strictly regulated by CsgB, an accessory protein whose gene is localized to the same operon as the CsgA gene, and that serves as an obligatory nucleation seed for CsgA polymerization (Shu et al., 2012). CsgB rapidly assembles into beta-sheet rich oligomers that massively catalyze the transition of inherently unstructured CsgA monomers into amyloid. Interestingly, in vitro isolated CsgA can separately polymerize into amyloid fibrils also in the absence of CsgB. This difference suggests that curli amyloidogenesis in living cells is under the stringent control of a dedicated trigger which actually restricts the assembly of amyloids to an immediate physiological request.

In mammalian organisms, a functionally controlled amyloid growth process has been proposed for melanosomes, a type of organelles used for the synthesis and storage of melanin body pigments. The transmembrane protein Pmel17 was identified as a major component of amyloid fibers that organize in linear arrays through the length of the organelle (Raposo et al., 2001), and functionally serve as melanin deposits. Pmel17 is a multidomain protein that undergoes multiple sequential posttranslatory processing and protease cleavage steps on its way to becoming functionally incorporated into amyloid fibers on the membrane of mature melanosomes (Leonhardt et al., 2013). One critical point is the late cleavage and extralumenal release of the $\mathrm{N}$-terminally located regions RPT (an imperfect repeat region), PKD (polycstic kidney disease domain), and NTR (N-terminal region). RPT and PKD represent soluble core amyloidogenic fragments that can assemble into fibers once cleaved, while NTR is not amyloidogenic, and seems to serve as a specific stabilizer of RPT and PKD during fibril growth. When this property of NTR is impaired, the fibrillogenic fragments are degraded and amyloid polymerization of RPT and PKD cannot occur.

Both mechanisms described above highlight a possible safeguard strategy by which the integrated generation of specific amyloid promoting factors simultaneously to amyloidogenic particles drives polymerization towards mature amyloid fibers instead of potentially harmful misfolded intermediates. This provides a means to exploiting stringently controlled amyloid polymerization for functional purposes.

One further example for function-associated amyloidogenesis comes from mammalian secretory granules of pituitary glands, where a set of peptide hormones accumulate in form of aggregates with amyloid properties, being reactive to amyloid-specific immunodetection, ThioS and Congo Red staining, and with a typical cross-beta x-ray diffraction pattern (Maji et al., 2009). Interestingly, a variety of isolated peptide hormones is capable of amyloid fiber formation at moderately acidic $\mathrm{pH}$ and in the presence of glycosaminogylcans, two conditions similar to those within secretory granules, while partially resolubilising when exposed to extragranular conditions ( $\mathrm{pH}$ 7.4). This behavior leads to suggest that secretory granules can store hormones in form of tightly packed amyloids, releasing monomeric hormone units under determinate stimuli, which would obviate the 
need of a repeated de novo synthesis without affecting the immediate availability of the substance. The further confinement of hormone polymers within a coating membrane provides a means for cells to store amyloid under relatively innocuous conditions.

In spite of the strong pathologic link to disease, it appears that under certain conditions cells are also able to exploit the amyloid properties of prions for functional profit. Major mechanistic insights on prion function derive from the yeast Saccharomyces cerevisiae, an organism that ingeniously turns conformational variability underlying prionogenesis into selective advantage (Chernova et al., 2014). In yeast, the insurgence and propagation of new phenotypic traits is sometimes coupled to the ability of determinate proteins to convert from a native into an alternative conformation with a substantially altered original function. This type of conformational rearrangement occurs in a fashion typical of prions, in that the prion conformer (A) displays structural and physical features of amyloids, (B) catalyzes its own template-driven conversion, and (C) can be non-genetically transmitted. As prototypically shown for the yeast protein Sup35 (Tuite and Cox, 2006), a transition from a native $\left[\mathrm{PSI}^{-}\right]$into a self-perpetuating prion conformation [PSI+] is accompanied by a remarkable acquisition of novel cellular phenotypes, which can be ascribed to a functional loss when soluble Sup35, which is a release factor that controls the fidelity of ribosome translation termination, converts into unsoluble amyloid. Under selective pressure, the functional loss of Sup35 can turn into an advantage, as it improves the prevalence of cryptic phenotypes capable of coping with an altered environment (Halfmann et al., 2012). Even more intriguing, also prokaryotes appear to sustain prion inheritance, being able to propagate the [PSI+] phenotype over several generations under conditions that do not permit de novo prion formation (Yuan et al., 2014). This finding points to prion transmission as an ancient mechanism of inheritance.

Although such an impressive strategy shows that prions can be tolerated in principle, bargaining of phenotypic homoeostasis is hardly conceivable in neurons. First, the outspoken toxicity of prions in mammalian neurons overrides any possible adaptation to selective pressure within an evolutionary observable time scale. Second, mammalian cells lack essential regulators of yeast prion inheritance (e.g., the molecular chaperone hsp104).

With this in mind, it might sound heretical to speculate about prion-associated physiological benefits for mammalians. However, also in higher eukaryotes, polypeptides with bona fide prion properties exist more frequently than it might sound reasonable for a purely toxic agent. Algorithms trained to identify possible prion signatures could pinpoint one prevailing structural pattern to amino acid stretches of low structural complexity abounding in glutamine and/or asparagine residues. The validity of these predictions could be experimentally verified case-by-case for proteins from yeast as well as from higher eukaryotes (Alberti et al., 2009; Toombs et al., 2010; Couthouis et al., 2011). Interestingly, the isolated region (referred to as prion-like region PLR) is sufficient to confer self-perpetuating traits typical of yeast prions even when artificially fused to unrelated proteins, when interchanged between proteins, or when heterologuosly expressed in yeast (Sondheimer and Lindquist, 2000; Gilks et al., 2004; Li et al., 2014; Udan-Johns et al., 2014).

Such a typically modular architecture of prion-like regions comes along with an autonomous ability to inherently fold into amyloid-like conformations (Kato et al., 2012). Given that protein modules serve for a precise functional purpose, it can be expected that amyloid folding provides more than the structural blueprint of proteotoxicity. For the neuronal isoform of cytoplasmic polyadenylation element-binding protein (CPEB) from the aquatic snail Aplysia californica, the aggregation into an active polymer is essential to regulate the simultaneous processing of multiple RNA molecules in a spatially organized and highly coordinated fashion (Raveendra et al., 2013). Amyloid aggregation guides the local and reversible assembly of CPEB monomers at the synaptic ends of neurons, where this protein operates for long-term memory purposes. The resulting supramolecule is functionally active, showing a much higher RNA binding affinity than the monomeric units. Biostructural analyses have confirmed that functional CPEB aggregates display a typical amyloid conformation, consisting of a high beta-sheet content and an x-ray diffraction pattern at 4.7 and $10.7 \mathrm{~A}$. Importantly, the RNA-binding domain does not incorporate into amyloid fibers and remains solvent exposed, substantiating the hypothesis that only the prion-like region functions like an autonomous and specialized structural module.

In analogy, prion-like assembly is a functional aspect of RNA-binding protein FUS, a $53 \mathrm{kDa}$ protein with an aggregation propensity that is typically linked to the occurrence of unsoluble protein inclusions in amyotrophic lateral clerosis (ALS) and frontotemporal dementia (FTD; Shelkovnikova, 2013). In fundamental contrast to such a type of irreversible aggregation, some recent studies point to FUS self-assembly as a reversible, regulated, and explicitly functional process. Schwartz et al. describe one type of RNA-induced FUS polymers as characteristic amyloid beta-zipper structures with a significantly increased affinity for RNA polymerase II (RNAPolII) as compared to monomeric FUS (Schwartz et al., 2013). In a separate study, Kwon et al. suggest a biologically regulated nature of this interaction, showing that amyloid-like hydrogels (see Section Prion-like aggregation as an organizing principle of intracellular granule formation) obtained from isolated FUSPLR bind to RNAPolII in a mode that can be reversed by phosphorylation (Kwon et al., 2013). Further, by using a FUSPLR/GAL4 gene reporter construct, the authors highlight how mutations of PLR amino acid repeats $[\mathrm{G} / \mathrm{S}] \mathrm{Y}[\mathrm{G} / \mathrm{S}]$, which are critical for beta-zipper formation, compromise amyloidlike association and transcriptional activation to the same extent, demonstrating that FUS amyloid polymerization is tightly coupled to function. Moreover, a recent study identifies PLRmediated self-assembly of FUS as an essential process for chromatin binding and transcriptional activity (Yang et al., 2014). Although the authors do not specify the physical properties of the assemblies, the regulatory character of this biochemical process and mechanistic analogies to the 
RNAPolII complex legitimate the hypothesis of an amyloidlike polymerization. Consistent with such an assumption, the chromatin-associated oligomerisation step requires the presence of RNA, which might trigger amyloidogenesis as a functional prerequisite.

\section{PRION-LIKE AGGREGATION AS AN ORGANIZING PRINCIPLE OF INTRACELLULAR GRANULE FORMATION}

Intriguingly, both CPEB and FUS are representative RNA-binding proteins, a category of polypeptides ranking unsuspectedly high among predicted prion-like candidates. This finding is significant, because proteins such as FUS are constituents of RNA granules, a species of remarkably dynamic organelles that controls major key steps of RNA metabolism from synthesis to splicing, processing, stabilization and degradation (Thomas et al., 2011). While some of them are constitutive, other can generate de novo upon specific needs and disassemble afterwards. Such a remarkable plasticity is favored by the lack of a confining membrane, which allows for an uncomplicated interchange of molecules with the intracellular environment. Underlying this dynamics is the property of RNA-binding proteins to shuttle between separate subcellular compartments, to repartition between various types of RNA granules, and to dissociate from them in probable adaptation to selective cellular demand. Systems approaches on neuronal RNA granules suggest that these types of organelles share only little core protein similarities, supporting the fact that the majority of protein components associates transiently and specific to immediate functional requirements. (Fritzsche et al., 2013).

The frequency by which prion-like protein candidates seem to actively influence function, size, and cell number of RNA granules has led to the assumption that their PLRs might serve as rational protein-protein interfaces that naturally control condensation, growth, integrity and dynamic reorganization of these organelles by means of amyloid polymerization. Strong support comes from the observation that some isolated, recombinant PLRs from RNA granule components can spontaneously condensate in vitro into hydrogel-like particles with a fibrous morphology and amyloid-like structural properties (Kato et al., 2012). Unlike mature amyloid fibers from unsoluble inclusions, however, these cell-free assemblies are relatively fragile, and reversibly decompose into monomers already under semi-denaturing conditions. Yet, they are sufficiently stable to in vitro emulate morphogenesis and steady-state dynamics of RNA granules with staggering simplicity (Han et al., 2012; Weber and Brangwynne, 2012; Kwon et al., 2013): (A) they originate via self-assembly either upon concentration-dependent or templatedriven nucleation, (B) they undergo demixing phase separations typical of membrane-free organelles, (C) they are able to heterotypically incorporate or exchange additional RNA granuleassociated protein components, (D) they tend to associate preferentially with extended 3'-UTR mRNAs sequences, and (E) they respond to post-translatory modifications in a way that reflects physiologic regulation of RNA granules. These findings highlight the potential of PLR-containing proteins to reproduce major hallmarks of RNA granule biogenesis and function by accessing a polymer state which is morphologically close to amyloid, but completely reversible and therefore devoid of any stable higher order aggregates characteristic of pathologic prions. As these polymers unify basic physical properties of stable amyloids (self-organization, cross-beta structure) with reversibility and a minimal toxic hazard, they are potentially appealing for physiological use. First, the spontaneous polymerization of prion-like components can be initiated only upon an incisive conformational change, e.g., by molecules that act as nucleators. Second, polymerization comes along with a sharp phase transition from liquid to gel-like, which closely resembles physical processes of granule condensation in vivo (Dundr, 2012; Weber and Brangwynne, 2012). Third, by retaining the unique cross-beta amyloid structure, amyloidlike polymers allow for a tight polymer stacking, which can be useful when a locally restricted accumulation of proteins up to very high concentrations is biologically required. Fourth, their aggregation/deaggregation is susceptible to biochemical stimuli such as post-translatory modifications, allowing for a physiologically organized dynamics.

In principle, these attributes all comply with physical prerequisites of RNA granule assembly and disassembly, such as nucleation upon demand, steady-state association, and a precise spatial and temporal separation, suggesting mechanistic parallels between cell-free hydrogel aggregation and granule biogenesis in vivo. The analysis of stress granule (SG) dynamics provides particular support to this assumption. SG are one type of membraneless organelles that originate transiently in the cytosol upon different forms of cellular challenge, contributing to the arrest of mRNA translation in response to generic insults such as intoxication, UV-irradiation, oxidative stress and heat shock (Kedersha et al., 2013). When homeostasis is restored, these granules dissolve rapidly and completely.

The protein and RNA composition of SG is extremely heterogeneous and highly variable, with a growing number of proteins being identified as regulators. This dynamic constitution reflects a possible ability of SG to individually respond and adapt to various types of stimuli. Significantly, SG reversibly incorporate proteins from multiple stress signaling pathways, therefore becoming actively integrated into the circuitry of separate signaling cascades. Phosphorylation of eukaryotic initiation factor $2 \mathrm{a}$ (eIF2a), which represents an integrated response to different stress stimuli and is the best investigated trigger of SG assembly, abolishes translation initiation, causing polysome disruption and the passing over of untranslated mRNA to SG under persisting stress (Anderson and Kedersha, 2008). Upon a restored homeostasis, SG rapidly dissociate, thereby releasing bound mRNA for appropriate processing. Further SG components point to regulation of cell death during stress. The incorporation of the adaptor protein RACK1 into SG inhibits the activation of MTK1, a kinase that acts upstream of the p38/JNK apoptosis pathway (Arimoto et al., 2008). Similarly, upon binding to SG, ROCK1, a component of Rho GTPase signaling cascades, loses the ability to transduce apoptotic stimuli (Tsai and Wei, 2010). Finally, SG sequestration of TORC1, a component of the Target of Rapamycin (TOR) pathway, alters metabolism during nutrient deprivation (Wippich et al., 2013). All these effects can be reversed upon SG dissociation, in alignment with a regulatory 
nature of these interactions, which leads to ask how the SG proteome can adapt its composition to selected stimuli.

One possible explanation comes from the observation that several SG-associated signaling proteins can couple SG initiation to concomitant pathway-specific protein-protein interactions. As shown for dual specificity tyrosine-phosphorylation-regulated kinase 3 (DYRK3), this enzyme nucleates SG in response to a signal-induced concentration increase via an N-terminal low complexity region, which is concurrently required for the sequestration and functional inactivation of TORC1 (Wippich et al., 2013). As overexpressing the isolated N-terminal region is sufficient to simultaneously evoke both processes, it is likely that DYRK3 induces the condensation of granules specifically tailored to fit TOR signaling demands.

Although it is unclear whether DYRK3-mediated SG assembly actually involves amyloid-associated polymerization, it is intriguing to note how the majority of established SG-nucleating proteins have a significantly high predicted amyloidogenic propensity (Table 2 ). One more explicit indication comes from the study of the two prototypic SG nucleators TIA-1 and TIA-1 related (TIAR). Both proteins possess three distinct RNA binding domains (RRM1-3), and under normal conditions, they absolve splicing-associated roles in the nucleus, where TIA-1 has been described to recognize poly-uridine sequences to facilitate 5' splice site recognition by $\mathrm{U} 1$ small nuclear ribonuclein (Izquierdo et al., 2005; Singh et al., 2011). Under stress conditions, these proteins can sense the increase of translationally stalled mRNA by reversibly binding to AU-rich elements in the 3'UTR (Kedersha et al., 2000). They subsequently move to the cytosol and nucleate the assembly of SG, a process that requires their intact C-terminal Q/N-rich PLR region, a low structural complexity sequence with a high predicted prion score (Gilks et al., 2004; Couthouis et al., 2011). Accordingly, TIA-1 is capable of self-sustained transmission in yeast (Li et al., 2014), and it can associate into amyloid fibrils in vitro (Furukawa et al., 2009; Li et al., 2014). While the deletion of the PLR region completely abolishes SG assembly, its replacement with an extraneous PLR with similar aggregation properties (e.g., that of yeast prion Sup35) completely restores the ability (Gilks et al., 2004), which is a striking indication for prion-like aggregation as an inherent mechanism of SG self-organization. In close conjunction, aggregated TIA-1 acquires the ability of binding stalled ribosomes, suggesting that this protein mediates the efficient sequestration of abortive preinitiation complexes by nucleating SG assembly (Gilks et al., 2004). These data provide a further demonstration of how SG can be modeled in response to specific functional purposes, further suggesting that amyloids can serve as structural backbone and adapter modules of highly dynamic supramolecular machines.

\section{STRESS GRANULES MISASSEMBLY AS AN INHERENT RISK OF FUNCTIONAL PROTEIN AGGREGATION}

Intriguingly, the overexpression of an isolated TIA-1 PLR lacking the three RNA binding domains generates deteriorated aggregates which are no longer reversible, and refractory to SDS denaturation and protease digestion (Gilks et al., 2004), a pattern typical of pathogenic prions (see Section
Table 2 | Amyloidogenic propensity of SG nucleating proteins (adapted from Kedersha et al., 2013) calculated by the PASTA algorithm, which evaluates the stability of putative cross-beta pairings between different amino acid stretches (Walsh et al., 2014).

Protein Lowest energy value
Ago2

Ataxin2

Caprin1

CPEB

DDX3

DYRK3

FASTK

FMR1

G3BP1

MEX3B

PARP1

PKR

PQBP1

DAZAP2

Pumilio

DHX36

Roquin

SMAUG

SMN

TIA1

TIAR

TTP
$-9.49$

$-9.06$

$-6.49$

$-7.07$

$-8.21$

$-6.77$

$-10.38$

$-6.94$

$-6.94$

$-7.44$

$-6.94$

$-6.37$

$-3.75$

$-4.84$

$-7.70$

$-13.24$

$-10.42$

$-7.25$

$-6.67$

$-6.12$

$-6.13$

$-4.9$
The list reports the best aggregation pairing energy values for the most aggregation prone peptides. Values below a threshold of -5 are considered confidential. Values of representative amyloidogenic peptides from PrP, aSyn and Abeta are $-16.04 ;-7.24$; and -8.86 , respectively.

Molecular pathways of amyloid propagation). This type of aggregates is not functional, being unable to recruit ribosomes, and insensitive towards conventional degradation (see Section Molecular catchers in the amyloid rye: heat shock proteins and proteolytic pathways), which leads to an unusual cytosolic persistence (several days instead of a few hours) and precipitation. This process anticipates the catastrophic consequences of an uncontrollable and irreversible aggregation, giving an impressive suggestion of why functional aggregation must imply reversibility. This observation is outstanding, considering that alterations in SG integrity, such as assembly/disassembly disequilibria or the improper incorporation of protein components correlate to the prevalence of organic disorders (Banfield et al., 2014). Indeed, in the cell, many regulatory networks are composed of abundant, but thermodynamically unstable (supersaturated) proteins, which are primarily vulnerable to the appearance of excessively stabilized aggregates (Ciryam et al., 2013). While soluble under homeostatic conditions, this type of proteins can easily tilt into unsoluble upon any unbuffered conformational perturbation (Xu et al., 2013). Olzscha et al. have emulated in situ the effects of amyloid overload (Olzscha et al., 2011). The exaggerated exposure of cells to artificially superstabilised amyloid particles caused the collapse of entire metastable protein pathways, affecting RNA metabolism, protein turnover, and mitochondrial integrity among others. All these activities are indeed gravely impaired in amyloid-associated neurodegenerative disorders, and significantly, supersaturated 
proteins abound within neurodegenerative disease pathways (Ciryam et al., 2013).

This concept can be extended to SG, as these organelles must preserve reversibility as a prerequisite for physiological function (Kedersha et al., 2000). Processes that modify the assembly/disassembly, and thereby the steady-state integrity of SG, have been associated to misfolding, mislocalisation, or sequestration of various SG components, such as TDP-43, FUS, and hnRNPA isoforms, which are all outstanding modifiers of inclusion body neuropathologies (Iguchi et al., 2013; Kim et al., 2013; Shelkovnikova, 2013). TDP-43 is a $43 \mathrm{kDa}$ protein originally identified as a transcriptional repressor of HIV-1 transactivation response element. It is aggregation prone (Johnson et al., 2009), and unsoluble intracellular inclusions containing this molecule can be found in patients suffering from FTD and ALS. This protein seems to absolve multiple RNA-devoted roles and it is predominantly nuclear, associating preferentially with splicing components. In the cytosol, endogenous TDP-43 interacts with components of the translation machinery, and it incorporates into SG upon various acute stress stimuli (arsenite intoxication, heat shock, proteasome inhibition). Although it is not a primary nucleator of SG, this protein influences size, morphology, and on/off kinetics of this organelle. Cells deprived of TDP-43 or mutations that decrease SG incorporation (R361S) lead to a significant delay in the appearance of SG, which are smaller in size and of less regular shape (Colombrita et al., 2009; Liu-Yesucevitz et al., 2010; McDonald et al., 2011).

While the localization of TDP-43 to SG is reversible and usually restricted to acute stress conditions, a forced cytosolic permanence of TDP-43, either upon persistent stress or due to genetic mutations, seems to potentiate the appearance of irreversible protein aggregates (Liu-Yesucevitz et al., 2010; Bentmann et al., 2012; Parker et al., 2012). In cells exposed to sustained stress, TDP-43 initially localizes to SG, but finally assembles into unsoluble cytoplasmic inclusions resistant to SG-disrupting chemicals such as cycloheximide (Parker et al., 2012). A similar effect was observed after the expression of disease-associated mutants G294A, A315T, Q331K, and Q343R (Figure 1), which all have an increased cytosolic/SG localization pattern (Liu-Yesucevitz et al., 2010) and a major aggregation propensity (Johnson et al., 2009; Chen et al., 2010; Guo et al., 2011). In the presence of these mutants, SG were more abundant upon induction, and in contrast to wildtype-TDP-43, they partially converted into unsoluble species. These findings suggest that under adverse conditions, the incorporation of TDP-43 into SG can favor their conversion from physiologically regulated reversible organelles into irreversible cytosolic aggregates.

Similarly to TDP-43, FUS is an RNA-binding protein with probable roles in transcriptional activation and gene splicing (Schwartz et al., 2012, 2013; Yang et al., 2014), and consistently, it resides predominantly in the nucleus. The association of wildtype FUS with SG seems to be much weaker and more stimulus selective than for TDP-43 (Acosta et al., 2014), but it becomes generally favored upon a forced cytosolic permanence, such as for the disease-associated variants R495X, R521C, R521L, all impairing nuclear localization of FUS (Figure 1). These mutants have an increased aggregation propensity, and readily incorporate into SG upon arsenite treatment (Bosco et al., 2010; Aulas et al., 2012; Bentmann et al., 2012; Baron et al., 2013; Acosta et al., 2014). In analogy to TDP-43, the interaction is still reversible, but with evident alterations in SG morphology and dynamics, as shown by ALS-linked FUS-R945X. This NLS lacking truncation mutant increases the number and size of SG upon persisting stress, although initially disfavoring the assembly of SG (Bosco et al., 2010). Intriguingly, natural or artificial FUS mutants (e.g., R522G) fail to incorporate into SG, accumulating as separate cytosolic inclusions with morphological and dynamic features distinct from SG, and more reminiscent of intracellular bodies associated to neuropatholgic disorders (Shelkovnikova et al., 2014). In contrast to SG, this type of FUS inclusions has a more irregular shape, a much higher kinetic stability than SG, the ability to fuse with each other, and it barely contains SG markers. These findings lead to speculate that SG might transiently incorporate mislocalised and aggregation-prone variants of FUS to prevent aggregation during acute stress, however at the increased risk of an own overload and subsequent precipitation when the stress stimuli become excessive.

Mislocalisation of FUS seems to have multiple pathologic overlaps, as its prolonged extranuclear permanence, while affecting SG dynamics, also prevents this protein from correctly absolving typically nuclear functions. Wildtype FUS can bind to transcriptionally active chromatin, acting as a possible transcriptional regulator (Yang et al., 2014). This property is challenged when nuclear localization is impaired, as for FUSR495X, which is transcriptionally far less active than the wildytpe. Moreover, mislocalised FUS is no longer able to assist the biogenesis of gems, a class of nuclear RNA processing granules with major roles in spliceosome organization (Yamazaki et al., 2012), leading to a condition closely similar to the motoneuron disorder spinal muscular atrophy (SMA). This type of disease is otherwise linked to mutations in SMN, a protein which is essential for the structural and functional integrity of gems (Liu and Dreyfuss, 1996). It was shown that FUS can interact with SMN, contributing to the regulation of homeostatic gem assembly, a property which was no longer observable for the R495X truncation variant. Therefore, one defect might link the occurrence of cytoplasmic inclusions in ALS with the loss of nuclear gems in SMA, suggesting a converging mechanism for both diseases.

As TDP-43, FUS and hnRNPA are amyloidogenic (Table 1), it is relevant to ask how this property might influence their association with SG. Some more amyloidogenic protein variants exhibit indeed a significantly enhanced tendency to incorporate into SG (Figure 1), suggesting a causal link between both processes. Recently discovered ALS/multisystem proteinopathyassociated hnRNPA1 and hnRNPA2B1 variants (D262V and D290V, respectively) show an increased tendency to form steric zippers, the complementary beta-stranded backbone of amyloid fibers, in concomitance to a significantly more pronounced recruitment to SG (Kim et al., 2013; Figure 1). Moreover, the removal of multiple tyrosine residues at different positions of [G/S]Y[G/S] beta-zipper nucleating repeats of FUS-PLR abolishes 


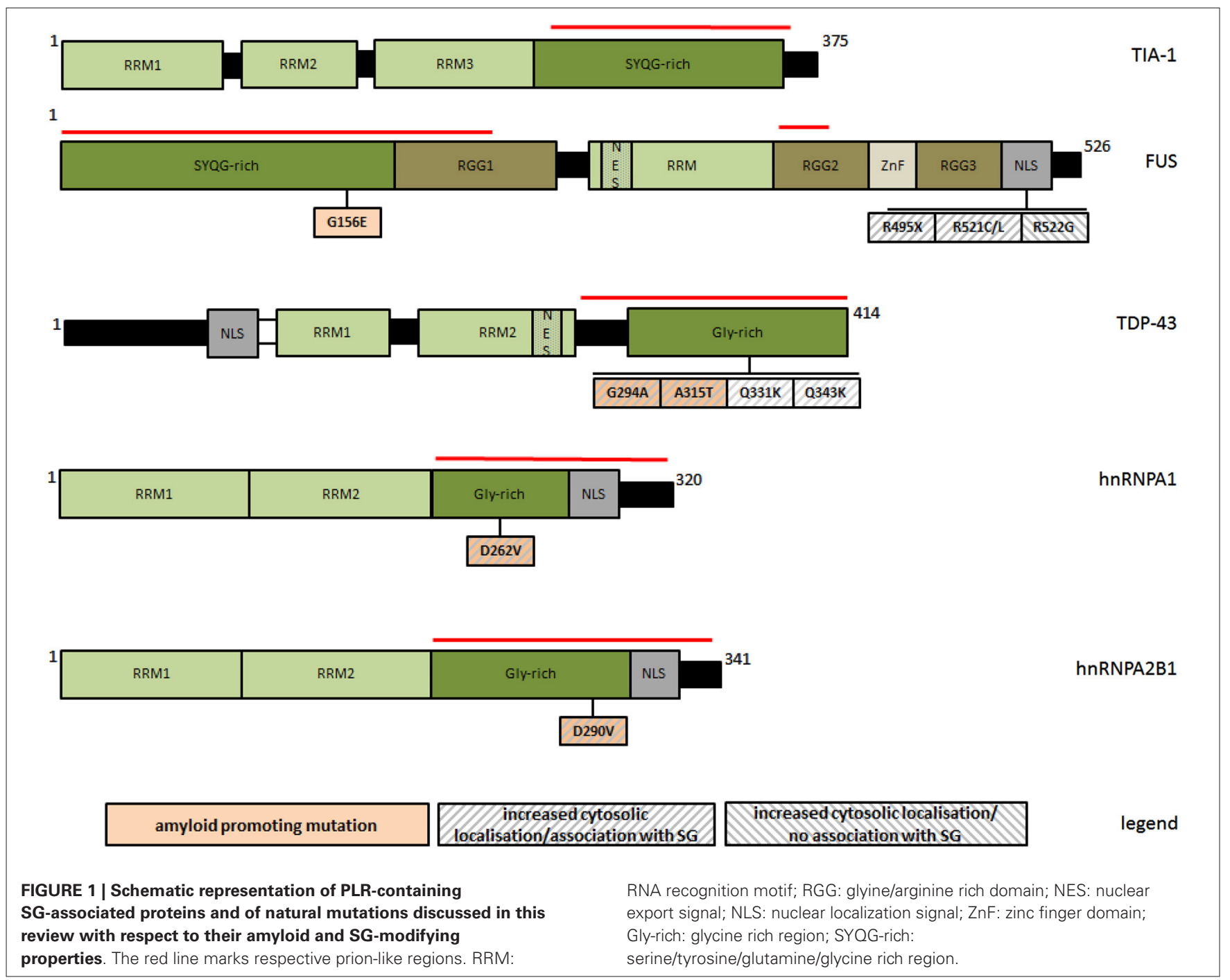

both amyloid-like hydrogel polymerization (see Section Prionlike aggregation as an organizing principle of intracellular granule formation) and the incorporation into SG (Kato et al., 2012). Such an explicit relationship has not been demonstrated for TDP-43, although two natural mutations (G294A and A315T) have been separately described as more amyloidogenic (Chen et al., 2010; Guo et al., 2011) and more prone to associate with SG (LiuYesucevitz et al., 2010; Figure 1).

SG dynamics is also challenged by amyloidogenic proteins without a "canonical" prion-like region, such as htt or tau. Huntington Disease (HD) key pathogen htt displays a highly variable polyglutamine (polyQ) sequence that develops amyloidogenic and pathogenic properties above a threshold length of around 40 glutamines. In a mouse model for HD, the intracellular aggregation of a $42 \mathrm{Q}$ htt variant caused a massive co-aggregation and functional inactivation of TIA-1 (Furukawa et al., 2009). This process is likely to involve crossnucleation, as htt-derived amyloid fibers were able to seed for TIA-1 amyloids. Intriguingly, non-aggregating htt (25Q) seems to physiologically associate with components of RNA granules without compromising their activity (Savas et al., 2010), suggesting that htt evolves from granule-stabilizing into granule-destabilizing upon the acquisition of amyloidogenic traits. A similar disease-linked association likely occurs for hyperphosphorylated tau, which co-localizes with TIA-1 positive SGs in animal disease models (Vanderweyde et al., 2012). Interestingly, this interaction is dependent on the progression of the disease, being weak to moderate at the beginning, and increasing with disease severity.

Collectively, these data suggest that SG are extremely sensitive to processes affecting their transient nature, with an excessive stabilization leading them to evolve into irreversible toxic aggregates comparable to those of artificially stabilized amyloids (Olzscha et al., 2011). This might explain their rigorously time-, space- and stimulus-confined mode of action.

\section{THE BOUNDARIES OF TOLERATED PROTEIN AGGREGATION}

The previous section has capitalized how functional aggregation occurs incredibly close to catastrophe, and how the boundaries between function and toxicity are startlingly fragile. This leads 
to wonder what kind of strategies cells adopt to physiologically benefit of a process that goes hand in hand with major system failure.

Gsponer and Babu propose that aggregation can indeed defy proteotoxicity as long as it is controllable, reversible, and temporally and spatially localized (Gsponer and Babu, 2012). They point to the existence of multilevel control mechanisms by which cells manage to keep the concentration of aggregation-prone proteins constitutively below a critical threshold. Aggregation can then be driven by a self-organized monomer-polymer transition following Le-Chatelier's principle basically by increasing protein abundance upon specific demand. Such a mechanism would apply to explain the dynamic consistency of SG and other transient cellular aggregates, which might form and disrupt upon precise fluctuations of their protein components.

In substance, the fates of aggregation-prone proteins are governed at nucleic acid and protein level. At nucleic acid level, a stringent control of transcripts aims at reducing the expression of aggregation-prone proteins to an essential minimum. The physical regulation of mRNAs encoding aggregation-prone proteins is fundamentally different from mRNAs of nonaggregating proteins. The former type of mRNA has a slower transcription rate, it is preferentially escorted by regulatory RNAbinding proteins, it has a higher tendency to form secondary structure retarding the initiation of translation, and it has mediocre translation efficiency due to a less optimal codon usage and a lower ribosome density per transcript (Gsponer and Babu, 2012).

At protein level, a scrupulous surveillance of protein function and folding quality aims at counteracting the accumulation of misfolded and dysfunctional polypeptides (Hipp et al., 2014). Cells are equipped with high-fidelity machineries that systematically minimize the accumulation of misfolded proteins by coupling protein quality control and clearance. These processes are kept in balance by an intensive cross-talk between molecular chaperones and different degradation machineries. Molecular chaperones are proteins capable of discriminating native from non-native and aggregation-prone protein conformations, selecting irreparably misfolded polypeptides for degradation. This decisional power is fundamental to neutralize adverse effects of irreversibly misfolded proteins which have been rated irrecoverable after failing chaperone quality screening. In this case, substrates are redirected from folding to degradation.

\section{MOLECULAR CATCHERS IN THE AMYLOID RYE: HEAT SHOCK PROTEINS AND PROTEOLYTIC PATHWAYS}

Heat shock proteins (hsps) are a class of representative and ubiquitously expressed, structurally unrelated molecular chaperones which bind to unfolded or partially folded polypeptides preventing them from aggregation. Hsps act in frequent combination with each other, thereby providing a powerful relay team, which is equipped with numerous accessory proteins accounting for fine-tuning and coordination.

Two potent modifiers of amyloid fiber assembly are hsp90 and hsp70. While hsp70 family chaperones assist generic protein folding processes (e.g., during polypeptide biosynthesis or membrane translocation), hsp90 acts especially to stabilize proteins in a near-native, yet unstable conformation until their full structural maturation. The rationale behind the stabilization of partially rather than entirely unfolded polypeptides is to locally protect unstable or destabilized regions, e.g., during rearrangements that functionally require the transient exposure of hydrophobic moieties (e.g., during the activation of kinases or steroid hormone receptors). Hsp90 thus prevents the collapse or the aggregation of metastable regions by keeping them in a stalled position (Eckl and Richter, 2013).

As hsp70 and hsp90 influence amyloid fiber assembly at substoichiometric amounts, it has been proposed that a transient interaction occurs already with low-abundance amyloid precursors in order to repartition them from toxic into non-toxic early during amyloidogenesis (Wacker et al., 2004; Evans et al., 2006; Falsone et al., 2009; Daturpalli et al., 2013).

Both chaperones require ATP for functioning, and although the sole presence of nucleotide-free hsp70 and hsp90 is sufficient to suppress amyloid fiber growth in vitro, it is only by consumption of ATP that these chaperones actively redirect oligomeric intermediates "on- pathway" for amyloid assembly (Falsone et al., 2009; Lotz et al., 2010). These findings underscore the importance of ATPase-modulating co-factors for a controlled processing of hazardous aggregates. Hsp70 requires a classic cooperation with co-chaperone hsp40 to efficiently neutralize toxic polyQ-htt in an energy-consuming fashion (Lotz et al., 2010). The underlying mechanism is the property of hsp40 to selectively recognize a specific subset of alternatively folded polyQ-htt aggregates originating during the initial amyloid growth lag phase, while leaving other aggregates unaffected. The targeted aggregates are antigenic for the conformational antibody A11, which is selective for "off-pathway" species. These are unable to template for fiber assembly, being most likely toxic. Hsp40 subsequently presents them to hsp70, and the resulting stimulation of the hsp70 ATPase leads to their active remodeling and "on-pathway" redirection for the assembly into less toxic mature fibers.

Several studies highlight the relationships between hsps and amyloid diseases. The deletion of hsp70 genes exacerbates pathogenesis of HD (Wacker et al., 2009), while the overexpression of hsp70 can reduce amyloid-related phenotypes (Klucken et al., 2004). Hsp90 was found in association with polyQ-repeat expansions, showing a high affinity for polyQexpanded androgen receptor (AR), a pathogenic variant in spinal and bulbar muscular atrophy (Waza et al., 2005). Binding to wild type AR was more transient, and polyQ-AR was preferentially degraded after disrupting this interaction.

The expression of hsp70 and hsp90 is frequently perturbed in neurodegenerative disorders, and both proteins can be recovered from different cytoplasmic inclusions along with other types of chaperones (Hauser et al., 2005). This is consistent with the observation that a persistent exposure to aggregates causes the precipitation of major heat shock proteins, which is equal to a complete failure of protein folding pathways (Olzscha et al., 2011). With respect to SG, hsp90 and hsp70 supervise physiologic assembly of these granules by physically stabilizing separate components (Pare et al., 2009; Udan-Johns et al., 2014), 
but they are apparently unable to counteract excessive on/off disequilibria, e.g., the accumulation of aberrantly stable TIA-1 aggregates. Unlike full-length TIA-1, fragments from the prionlike region of TIA-1 lead to more stable intracellular aggregates resistant to disaggregation (Gilks et al., 2004; see Section Stress Granules misassembly as an inherent risk of functional protein aggregation). Although the cell reacts by increasing the levels of some endogenous hsps, it is only the artificial overexpression of hsp70 that efficiently reverses the aggregation of TIA-1 prionlike region. Otherwise, the endogenous increase of hsps is not sufficient to impede the formation of intracellular inclusions and the concomitant co-precipitation of hsps. This suggests that chaperones can neutralize acute proteotoxic burden, but not a chronic overload.

In this context, it was found that hsp70 is more inclined to precipitate depending on the state of bound nucleotide (Roodveldt et al., 2009), implying that a functioning nucleotide turnover is essential to guarantee the stability of the cycle. This constitutes a far-reaching challenge, as any stalling of the hsp70 cycle might come along with chaperone deprivation, leading to a derangement of protein folding homeostasis. Generally, such a scenario might be evoked by any form of energetic misbalance, such as mitochondrial impairment, as frequently observed in neurodegeneration (Pathak et al., 2013).

In close relation, pathologically stabilized amyloid species appear to compete with physiological substrates for binding to hsps. As shown for aSyn, stable oligomers can inhibit hsp70, which is therefore no longer capable of functionally folding other substrates (Hinault et al., 2010). Similarly, pathologic tau displaces TDP-43 from cdc37, a dedicated hsp90 co-chaperone. Under normal conditions, hsp90 binds to and stabilizes TDP43 , and the pharmacologic inhibition of hsp90 primes TDP43 for degradation (Falsone et al., 2007; Zhang et al., 2010). In cooperation, hsp90 and cdc37 regulate TDP-43 turnover and the autophagic clearance of cleaved TDP-43 (Jinwal et al., 2012). However, the inhibition of hsp $90 / \mathrm{cdc} 37$ activity by hyperphosphorylated tau leads to the cytosolic accumulation of TDP-43 fragments, which eventually precipitate forming inclusions typical of ALS and FTD.

Hsp70 and hsp90 are closely interlaced with protein degradation, and both chaperones possess the ability to redirect toxic aggregates to degradation (Hipp et al., 2014). Consistently, degrading pathways take over misfolded polypeptides which have been sorted for proteolytic clearance. These are essentially the ubiquitin-proteasome system (UPS), chaperone-mediated autophagy (CMA), and macroautophagy (MA). The UPS is constituted of the core protease machinery called $26 \mathrm{~S}$ proteasome, and a series of enzyme classes controlling substrate recognition, selection and targeting. For proteasome degradation, proteins have to be covalently marked by ubiquitin, a protein that is frequently found within protein inclusions (Dantuma and Bott, 2014). CMA consists in targeting polypeptides to the surface of lysosomes for their specific translocation through the membrane and the subsequent degradation. MA consists in the engulfment of a selected cargo into a double-membrane vesicle, with subsequent fusion to endosomes or directly to lysosomes. All these degradation mechanisms are directly involved in the clearance of amyloid aggregates at different stages. Partially redundant overlaps between proteolytic pathways additionally provide a compensatory advantage, since one malfunctioning complex can be usually backed by the mutual activation of at least another complex, keeping the toxic burden innocuously low. Such a fail-safe strategy is very effective at intransigently counteracting the risks arising from protein misfolding. Indeed, the entire amyloid folding landscape is rigorously subjected to this type of control. With functional aggregation occurring within supervised boundaries, pathogenic drifts towards misfolding can be timely suppressed and potentially toxic aggregates can be delivered to the most qualified clearance system. By these means, the cell can broadly manage the turnover of different physical species of protein aggregates in the most convenient way (Wang et al., 2009; Ebrahimi-Fakhari et al., 2011; Koga et al., 2011; Scotter et al., 2014). The UPS controls the homeostatic turnover of single monomeric proteins, whereas larger soluble or unsoluble aggregates require bulk autophagy. Therefore, proteins that aggregate in consequence to a single-molecule degradation failure can be removed by autophagy depending on size, morphology, and stability. Collectively, these systems provide a regulatory basis for functional aggregation, as they can reversibly shift monomer-oligomer transitions by regulating the turnover, and therefore the effective cellular concentration of each component. The aggregation of TDP-43, for example, can be kept in physiologic equilibrium by the interplay of UPS and autophagy, whereby monomeric TDP-43 can be degraded by the proteasome and soluble oligomers become targeted by MA (Scotter et al., 2014).

UPS degradation of soluble monomers seems to prevail under homeostatic conditions, and consistently, amyloidogenic proteins are substrates of various E3 ubiquitin ligases (Kumar et al., 2012). For aSyn, the degree of ubiquitylation affects amyloid aggregation in a way that reminds of active amyloid repartitioning preceding proteolytic clearance (Haj-Yahya et al., 2013), with ubiquitin chain length regulating stability, aggregation, phosphorylation, and clearance.

While ubiquitylation usually occurs on internal lysine residues, some disease-associated fragments from tau, aSyn, TDP-43 and Abeta can also undergo an unusual N-terminal ubiquitylation (Brower et al., 2013). This form of modification, known as $\mathrm{N}$-end rule pathway, consists of polyubiquitylation of N-terminal arginine residues by specific E3 ligases called N-recognins. Upon their conjugation, each of these fragments undergoes rapid proteasomal degradation, which impedes an excessive accumulation of these highly aggregation-prone and proteopathic species. For Abeta fragments, an additional N-terminal argininylation configures these peptides for the subsequent ubiquitin conjugation step.

These findings highlight the predominant role of ubiquitinmediated degradation in neuroprotection. Proteasome dysfunction seems central to neurodegeneration, and rather generic impairments of the UPS, whether pharmacologic, genetic, or physiologic, are sufficient for the unbiased appearance of diverse neurodegenerative phenotypes. The chemical UPS inhibition of dopaminergic cells favors the accumulation of Lewy-body like inclusions (Rideout et al., 2001). Likewise, the 
stereotactic injection of proteasome inhibitors into mice brains causes symptoms closely related to PD, including dopaminergic neuronal death, decreased motor activities, and the accumulation of inclusions positive to aSyn and ubiquitin (Xie et al., 2010). Moreover, the deletion of single proteasomal (but not autophagic) subunits is sufficient to evoke ALS symptoms in knock-out mice, leading to mislocalisation and precipitation of TDP-43 and FUS in motor neurons (Tashiro et al., 2012).

The integrity of the proteasome can be further challenged by an uncontrolled overload of amyloid aggregates. For Abeta, it was shown that aggregates can overturn the function of the UPS by physically interacting with proteasome subunits. Zhao and Yang suggest that a decreased proteasome activity is not due to inhibition, but rather to the competition of natural proteasome substrates with increasing concentrations of amyloid aggregates, as shown for Abeta peptide (Zhao and Yang, 2010). Similarly, the intracellular accumulation of TDP-43 or aSyn aggregates comes along with massive UPS dysfunction (Nonaka et al., 2013; Tanik et al., 2013). These considerations underscore the importance of a compensatory cross-talk between each single proteolytic pathway, whereby stimulating one separate degradation machinery can efficiently rescue malfunctions of the other pathways (Xilouri et al., 2013). By these means, aggregates that become renitent to conventional disposal can be passed over for alternative clearance. aSyn, which is usually cleared by the UPS under normal conditions, can be passed over to MA during particular cellular challenges (EbrahimiFakhari et al., 2011). In HD, a failed segregation of cytosolic cargo correlates with a marked increase of CMA components (Koga et al., 2011). An effect in the opposite direction is observed for disease-linked tau fragments, as the failure to process them via CMA leads to the activation of MA (Wang et al., 2009).

While the folding/degradation machineries presented above represent major aggregate modifying pathways, the recent discovery of the protein class MOAG-4/SERF suggests also the existence of more selective cellular mechanisms. MOAG-4/SERF possesses the unique ability to distinguish between amyloid and non-amyloid/amorphous aggregation, acting as a potent amyloid promoting factor (Falsone et al., 2012). One possible mechanistic interpretation of this property comes from the observation that the human homologue SERF1 binds to the C-terminal region of aSyn, which usually shields the central amyloidogenic region of this protein (Dedmon et al., 2005). The exposure of amyloidogenic core regions would thereby facilitate amyloid self-assembly. Intriguingly, the absence/presence of MOAG/SERF has pronounced effects on the proteotoxicity of intracellular htt, Abeta and aSyn aggregates in different model organisms. In C. elegans, aggregation and toxicity of polyQ expansions change in relation to the ageing-dependent expression levels of the orthologue MOAG-4 (van Ham et al., 2010). Silencing of MOAG-4 leads to a suppression of polyQ aggregation and toxicity, while the overexpression significantly aggravates toxicity, shifting polyQ towards compact misfolding intermediates. This effect is independent of conventional amyloid modifying pathways, as it is not influenced by alterations of the heat shock response, the UPS, or autophagy.
At this time, a more defined functional classification of MOAG/SERF is precluded by to the lack of detailed functional data. Of note, human homologues SERF1 and SERF2 share low-level homology with the RNA-binding domain of Matrin3 (Scharf et al., 1998) a protein that colocalises with small nuclear ribonucleoproteins (snRNPs), interacts with TDP-43, and has been recently identified as a novel disease marker for some rare forms of ALS (Johnson et al., 2014). This might suggest a possible role in RNA-associated (pathologic) processes.

\section{CONCLUDING REMARKS}

The purely pathological significance of amyloid protein aggregation has been questioned by the discovery of physiological processes that exploit some aspects of amyloid polymerization apparently for functional purposes. The structural and mechanistic similarity between pathologic and functional particles, however, anticipates that benefits of amyloid aggregation go hand in hand with toxicity. Despite these imminent hazards, the cell seems to tolerate aggregation as long as strictly confined within spatially and temporally delimited boundaries, as defined by inherently low transcription and translation rates, localized changes in protein levels, and a high protein quality control and turnover. By these means, aggregation-prone polypeptides are subjected to an exceptional physical and biological supervision at almost every level of cellular life. Yet, surveillance systems can fail upon chronic exposure to abnormally resistant aggregates, and in spite of some considerable functional backup, multiple simultaneous dysfunctions can tilt the equilibrium from functional into toxic. It is therefore conceivable, that amyloid polymerization is physiological, as long as the cell is capable of buffering any inherent toxicity. The occurrence of multiple system failures, as for example during cell senescence or upon extraordinary cellular challenges, might lead to the prevalence of toxic phenotypes, reflecting the multifactorial nature of the associated clinical conditions.

\section{ACKNOWLEDGMENTS}

This work was funded by the Austrian Science Fund (FWF):P22400 to SFF. Due to the outstanding amount of literature in this field, we apologize to all the authors who escaped our attention and whose studies were not considered for appropriate discussion.

\section{REFERENCES}

Acosta, J. R., Goldsbury, C., Winnick, C., Badrock, A. P., Fraser, S. T., Laird, A. S., et al. (2014). Mutant human FUS is ubiquitously mislocalized and generates persistent stress granules in primary cultured transgenic zebrafish cells. PLoS One 9:e90572. doi: 10.1371/journal.pone.0090572

Alberti, S., Halfmann, R., King, O., Kapila, A., and Lindquist, S. (2009). A systematic survey identifies prions and illuminates sequence features of prionogenic proteins. Cell 137, 146-158. doi: 10.1016/j.cell.2009.02.044

Alvarez-Erviti, L., Seow, Y., Schapira, A. H., Gardiner, C., Sargent, I. L., Wood, M. J., et al. (2011). Lysosomal dysfunction increases exosome-mediated alphasynuclein release and transmission. Neurobiol. Dis. 42, 360-367. doi: 10.1016/j. nbd.2011.01.029

Anderson, P., and Kedersha, N. (2008). Stress granules: the Tao of RNA triage. Trends Biochem. Sci. 33, 141-150. doi: 10.1016/j.tibs.2007.12.003 
Arimoto, K., Fukuda, H., Imajoh-Ohmi, S., Saito, H., and Takekawa, M. (2008). Formation of stress granules inhibits apoptosis by suppressing stress-responsive MAPK pathways. Nat. Cell Biol. 10, 1324-1332. doi: 10.1038/ncb1791

Aulas, A., Stabile, S., and Vande Velde, C. (2012). Endogenous TDP-43, but not FUS, contributes to stress granule assembly via G3BP. Mol. Neurodegener. 7:54. doi: 10.1186/1750-1326-7-54

Aulić, S., Le, T. T., Moda, F., Abounit, S., Corvaglia, S., Casalis, L., et al. (2014). Defined $\alpha$-synuclein prion-like molecular assemblies spreading in cell culture. BMC Neurosci. 15:69. doi: 10.1186/1471-2202-15-69

Banfield, B. W., Mouland, A. J., and McCormick, C. (2014). 1st international symposium on stress-associated RNA granules in human disease and viral infection. Viruses 6, 3500-3513. doi: 10.3390/v6093500

Baron, D. M., Kaushansky, L. J., Ward, C. L., Sama, R. R., Chian, R. J., Boggio, K. J., et al. (2013). Amyotrophic lateral sclerosis-linked FUS/TLS alters stress granule assembly and dynamics. Mol. Neurodegener. 8:30. doi: 10.1186/17501326-8-30

Bentmann, E., Neumann, M., Tahirovic, S., Rodde, R., Dormann, D., and Haass, C. (2012). Requirements for stress granule recruitment of fused in sarcoma (FUS) and TAR DNA-binding protein of 43 kDa (TDP-43). J. Biol. Chem. 287, 2307923094. doi: 10.1074/jbc.M111.328757

Bosco, D. A., Lemay, N., Ko, H. K., Zhou, H., Burke, C., and Kwiatkowski, T. J. Jr., et al. (2010). Mutant FUS proteins that cause amyotrophic lateral sclerosis incorporate into stress granules. Hum. Mol. Genet. 19, 4160-4175. doi: 10. 1093/hmg/ddq335

Bousset, L., Pieri, L., Ruiz-Arlandis, G., Gath, J., Jensen, P. H., Habenstein, B., et al. (2013). Structural and functional characterization of two alpha-synuclein strains. Nat. Commun. 4:2575. doi: 10.1038/ncomms3575

Braak, H., Alafuzoff, I., Arzberger, T., Kretzschmar, H., and Del Tredici, K. (2006). Staging of Alzheimer disease-associated neurofibrillary pathology using paraffin sections and immunocytochemistry. Acta Neuropathol. 11, 389-404. doi: 10. 1007/s00401-006-0127-Z

Brower, C. S., Piatkov, K. I., and Varshavsky, A. (2013). Neurodegenerationassociated protein fragments as short-lived substrates of the $\mathrm{N}$-end rule pathway. Mol. Cell 50, 161-171. doi: 10.1016/j.molcel.2013.02.009

Chen, A. K., Lin, R. Y., Hsieh, E. Z., Tu, P. H., Chen, R. P., Liao, T. Y., et al. (2010). Induction of amyloid fibrils by the C-terminal fragments of TDP-43 in amyotrophic lateral sclerosis. J. Am. Chem. Soc. 132, 1186-1187. doi: 10. 1021/ja9066207

Chernova, T. A., Wilkinson, K. D., and Chernoff, Y. O. (2014). Physiological and environmental control of yeast prions. FEMS Microbiol. Rev. 38, 326-344. doi: 10.1111/1574-6976.12053

Christianson, H. C., Svensson, K. J., van Kuppevelt, T. H., Li, J. P., and Belting, M. (2013). Cancer cell exosomes depend on cell-surface heparan sulfate proteoglycans for their internalization and functional activity. Proc. Natl. Acad. Sci. US A 110, 17380-17385. doi: 10.1073/pnas.1304266110

Ciryam, P., Tartaglia, G. G., Morimoto, R. I., Dobson, C. M., and Vendruscolo, M. (2013). Widespread aggregation and neurodegenerative diseases are associated with supersaturated proteins. Cell Rep. 5, 781-790. doi: 10.1016/j.celrep.2013. 09.043

Colombrita, C., Zennaro, E., Fallini, C., Weber, M., Sommacal, A., Buratti, E., et al. (2009). TDP-43 is recruited to stress granules in conditions of oxidative insult. J. Neurochem. 111, 1051-1061. doi: 10.1111/j.1471-4159.2009.06383.x

Couthouis, J., Hart, M. P., Shorter, J., DeJesus-Hernandez, M., Erion, R., Oristano, R., et al. (2011). A yeast functional screen predicts new candidate ALS disease genes. Proc. Natl. Acad. Sci. U S A 108, 20881-20890. doi: 10.1073/pnas. 1109434108

Dantuma, N. P., and Bott, L. C. (2014). The ubiquitin-proteasome system in neurodegenerative diseases: precipitating factor, yet part of the solution. Front. Mol. Neurosci. 7:70. doi: 10.3389/fnmol.2014.00070

Danzer, K. M., Kranich, L. R., Ruf, W. P., Cagsal-Getkin, O., Winslow, A. R., Zhu, L., et al. (2012). Exosomal cell-to-cell transmission of alpha synuclein oligomers. Mol. Neurodegener. 7:42. doi: 10.1186/1750-1326-7-42

Daturpalli, S., Waudby, C. A., Meehan, S., and Jackson, S. E. (2013). Hsp90 inhibits $\alpha$-synuclein aggregation by interacting with soluble oligomers. J. Mol. Biol. 425, 4614-4628. doi: 10.1016/j.jmb.2013.08.006

Dedmon, M. M., Lindorff-Larsen, K., Christodoulou, J., Vendruscolo, M., and Dobson, C. M. (2005). Mapping long-range interactions in alpha-synuclein using spin-label NMR and ensemble molecular dynamics simulations. J. Am. Chem. Soc. 127, 476-477. doi: 10.1021/ja044834j
DiDonato, M., Craig, L., Huff, M. E., Thayer, M. M., Cardoso, R. M., Kassmann, C. J., et al. (2003). ALS mutants of human superoxide dismutase form fibrous aggregates via framework destabilization. J. Mol. Biol. 332, 601-615. doi: 10. 1016/s0022-2836(03)00889-1

Dueholm, M. S., Nielsen, P. H., Chapman, M., and Otzen, D. (2013). "Functional amyloids in bacteria," in Amyloid Fibrils and Prefibrillar Aggregates's, ed D. E. Otzen (Weinheim, Germany: Wiley-VCH), 411-438.

Dundr, M. (2012). Nuclear bodies: multifunctional companions of the genome. Curr. Opin. Cell Biol. 24, 415-422. doi: 10.1016/j.ceb.2012.03.010

Ebrahimi-Fakhari, D., Cantuti-Castelvetri, I., Fan, Z., Rockenstein, E., Masliah, E., Hyman, B. T., et al. (2011). Distinct roles in vivo for the ubiquitinproteasome system and the autophagy-lysosomal pathway in the degradation of $\alpha$-synuclein. J. Neurosci. 31, 14508-14520. doi: 10.1523/JNEUROSCI.1560-11. 2011

Eckl, J. M., and Richter, K. (2013). Functions of the Hsp90 chaperone system: lifting client proteins to new heights. Int. J. Biochem. Mol. Biol. 4, 157-165.

Eichner, T., and Radford, S. E. (2011). A diversity of assembly mechanisms of a generic amyloid fold. Mol. Cell 43, 8-18. doi: 10.1016/j.molcel.2011.05.012

Eisenberg, D., and Jucker, M. (2012). The amyloid state of proteins in human diseases. Cell 148, 1188-1203. doi: 10.1016/j.cell.2012.02.022

Emmanouilidou, E., Melachroinou, K., Roumeliotis, T., Garbis, S. D., Ntzouni, M., Margaritis, L. H., et al. (2010). Cell-produced alpha-synuclein is secreted in a calcium-dependent manner by exosomes and impacts neuronal survival. $J$. Neurosci. 30, 6838-6851. doi: 10.1523/JNEUROSCI.5699-09.2010

Evans, C. G., Wisén, S., and Gestwicki, J. E. (2006). Heat shock proteins 70 and 90 inhibit early stages of amyloid beta-(1-42) aggregation in vitro. J. Biol. Chem. 281, 33182-33191. doi: 10.1074/jbc.m606192200

Falsone, S. F., Gesslbauer, B., Rek, A., and Kungl, A. J. (2007). A proteomic approach towards the Hsp90-dependent ubiquitinylated proteome. Proteomics 7, 23752383. doi: 10.1002/pmic.200600996

Falsone, S. F., Kungl, A. J., Rek, A., Cappai, R., and Zangger, K. (2009). The molecular chaperone Hsp90 modulates intermediate steps of amyloid assembly of the Parkinson-related protein alpha-synuclein. J. Biol. Chem. 284, 3119031199. doi: 10.1074/jbc.M109.057240

Falsone, S. F., Meyer, N. H., Schrank, E., Leitinger, G., Pham, C. L., FoderoTavoletti, M. T., et al. (2012). SERF protein is a direct modifier of amyloid fiber assembly. Cell Rep. 2, 358-371. doi: 10.1016/j.celrep.2012.06.012

Fang, Y. S., Tsai, K. J., Chang, Y. J., Kao, P., Woods, R., Kuo, P. H., et al. (2014). Fulllength TDP-43 forms toxic amyloid oligomers that are present in frontotemporal lobar dementia-TDP patients. Nat. Commun. 5:4824. doi: 10.1038/ ncomms 5824

Fevrier, B., Vilette, D., Archer, F., Loew, D., Faigle, W., Vidal, M., et al. (2004). Cells release prions in association with exosomes. Proc. Natl. Acad. Sci. U S A 101, 9683-9688. doi: 10.1073/pnas.0308413101

Fitzner, D., Schnaars, M., van Rossum, D., Krishnamoorthy, G., Dibaj, P., Bakhti, M., et al. (2011). Selective transfer of exosomes from oligodendrocytes to microglia by macropinocytosis. J. Cell Sci. 124, 447-458. doi: 10.1242/jcs.074088

Fritzsche, R., Karra, D., Bennett, K. L., Ang, F. Y., Heraud-Farlow, J. E., Tolino, M., et al. (2013). Interactome of two diverse RNA granules links mRNA localization to translational repression in neurons. Cell Rep. 5, 1749-1762. doi: 10.1016/j. celrep.2013.11.023

Furukawa, Y., Kaneko, K., Matsumoto, G., Kurosawa, M., and Nukina, N. (2009). Cross-seeding fibrillation of $\mathrm{Q} / \mathrm{N}$-rich proteins offers new pathomechanism of polyglutamine diseases. J. Neurosci. 29, 5153-5162. doi: 10.1523/JNEUROSCI. 0783-09.2009

Furukawa, Y., Kaneko, K., Watanabe, S., Yamanaka, K., and Nukina, N. (2011). A seeding reaction recapitulates intracellular formation of Sarkosyl-insoluble transactivation response element (TAR) DNA-binding protein-43 inclusions. J. Biol. Chem. 286, 18664-18672. doi: 10.1074/jbc.M111.231209

Gilks, N., Kedersha, N., Ayodele, M., Shen, L., Stoecklin, G., Dember, L. M., et al. (2004). Stress granule assembly is mediated by prion-like aggregation of TIA-1. Mol. Biol. Cell 15, 5383-5398. doi: 10.1091/mbc.e04-08-0715

Grad, L. I., Yerbury, J. J., Turner, B. J., Guest, W. C., Pokrishevsky, E., O’Neill, M. A., et al. (2014). Intercellular propagated misfolding of wild-type $\mathrm{Cu} / \mathrm{Zn}$ superoxide dismutase occurs via exosome-dependent and -independent mechanisms. Proc. Natl. Acad. Sci. U S A 111, 3620-3625. doi: 10.1073/pnas.1312245111

Gsponer, J., and Babu, M. M. (2012). Cellular strategies for regulating functional and nonfunctional protein aggregation. Cell Rep. 2, 1425-1437. doi: 10.1016/j. celrep.2012.09.036 
Guo, W., Chen, Y., Zhou, X., Kar, A., Ray, P., Chen, X., et al. (2011). An ALS-associated mutation affecting TDP-43 enhances protein aggregation, fibril formation and neurotoxicity. Nat. Struct. Mol. Biol. 18, 822-830. doi: 10. 1038/nsmb.2053

Guo, J. L., Covell, D. J., Daniels, J. P., Iba, M., Stieber, A., Zhang, B., et al. (2013). Distinct $\alpha$-synuclein strains differentially promote tau inclusions in neurons. Cell 154, 103-117. doi: 10.1016/j.cell.2013.05.057

Haj-Yahya, M., Fauvet, B., Herman-Bachinsky, Y., Hejjaoui, M., Bavikar, S. N., Karthikeyan, S. V., et al. (2013). Synthetic polyubiquitinated $\alpha$-Synuclein reveals important insights into the roles of the ubiquitin chain in regulating its pathophysiology. Proc. Natl. Acad. Sci. U S A 110, 17726-17731. doi: 10. 1073/pnas.1315654110

Halfmann, R., Jarosz, D. F., Jones, S. K., Chang, A., Lancaster, A. K., and Lindquist, S. (2012). Prions are a common mechanism for phenotypic inheritance in wild yeasts. Nature 482, 363-368. doi: 10.1038/nature10875

Han, T. W., Kato, M., Xie, S., Wu, L. C., Mirzaei, H., Pei, J., et al. (2012). Cell-free formation of RNA granules: bound RNAs identify features and components of cellular assemblies. Cell 149, 768-779. doi: 10.1016/j.cell.2012.04.016

Hauser, M. A., Li, Y. J., Xu, H., Noureddine, M. A., Shao, Y. S., Gullans, S. R., et al. (2005). Expression profiling of substantia nigra in Parkinson disease, progressive supranuclear palsy and frontotemporal dementia with parkinsonism. Arch. Neurol. 62, 917-921. doi: 10.1001/archneur.62.6.917

Hinault, M. P., Cuendet, A. F., Mattoo, R. U., Mensi, M., Dietler, G., Lashuel, H. A., et al. (2010). Stable alpha-synuclein oligomers strongly inhibit chaperone activity of the Hsp70 system by weak interactions with J-domain co-chaperones. J. Biol. Chem. 285, 38173-38182. doi: 10.1074/jbc.M110.127753

Hipp, M. S., Park, S. H., and Hartl, F. U. (2014). Proteostasis impairment in proteinmisfolding and -aggregation diseases. Trends Cell Biol. 24, 506-514. doi: 10. 1016/j.tcb.2014.05.003

Holmes, B. B., DeVos, S. L., Kfoury, N., Li, M., Jacks, R., Yanamandra, K., et al. (2013). Heparan sulfate proteoglycans mediate internalization and propagation of specific proteopathic seeds. Proc. Natl. Acad. Sci. U S A 110, E3138-E3147. doi: 10.1073/pnas. 1301440110

Horonchik, L., Tzaban, S., Ben-Zaken, O., Yedidia, Y., Rouvinski, A., Papy-Garcia, D., et al. (2005). Heparan sulfate is a cellular receptor for purified infectious prions. J. Biol. Chem. 280, 17062-17067. doi: 10.1074/jbc.m500122200

Iba, M., Guo, J. L., McBride, J. D., Zhang, B., Trojanowski, J. Q., and Lee, V. M. (2013). Synthetic tau fibrils mediate transmission of neurofibrillary tangles in a transgenic mouse model of Alzheimer's-like tauopathy. J. Neurosci. 33, 10241037. doi: 10.1523/JNEUROSCI.2642-12.2013

Iguchi, Y., Katsuno, M., Ikenaka, K., Ishigaki, S., and Sobue, G. (2013). Amyotrophic lateral sclerosis: an update on recent genetic insights. J. Neurol. 260, 2917-2927. doi: 10.1007/s00415-013-7112-y

Inoue, M., Watanabe, N., Matsuno, K., Sasaki, J., Tanaka, Y., and Hatanaka, H. (1991). Expression of a hybrid Cu/Zn-type superoxide dismutase which has high affinity for heparin-like proteoglycans on vascular endothelial cells. J. Biol. Chem. 266, 16409-16414.

Izquierdo, J. M., Majós, N., Bonnal, S., Martínez, C., Castelo, R., Guigó, R., et al. (2005). Regulation of Fas alternative splicing by antagonistic effects of TIA-1 and PTB on exon definition. Mol. Cell 19, 475-484. doi: 10.1016/j.molcel.2005. 06.015

Jinwal, U. K., Abisambra, J. F., Zhang, J., Dharia, S., O’Leary, J. C., Patel, T., et al. (2012). Cdc37/Hsp90 protein complex disruption triggers an autophagic clearance cascade for TDP-43 protein. J. Biol. Chem. 287, 24814-24820. doi: 10. 1074/jbc.M112.367268

Johnson, J. O., Pioro, E. P., Boehringer, A., Chia, R., Feit, H., Renton, A. E., et al. (2014). Mutations in the Matrin 3 gene cause familial amyotrophic lateral sclerosis. Nat. Neurosci. 17, 664-666. doi: 10.1038/nn.3688

Johnson, B. S., Snead, D., Lee, J. J., McCaffery, J. M., Shorter, J., and Gitler, A. D. (2009). TDP-43 is intrinsically aggregation-prone and amyotrophic lateral sclerosis-linked mutations accelerate aggregation and increase toxicity. J. Biol. Chem. 284, 20329-20339. doi: 10.1074/jbc.M109.010264

Kato, M., Han, T. W., Xie, S., Shi, K., Du, X., Wu, L. C., et al. (2012). Cell-free formation of RNA granules: low complexity sequence domains form dynamic fibers within hydrogels. Cell 149, 753-767. doi: 10.1016/j.cell.2012.04.017

Kedersha, N., Cho, M. R., Li, W., Yacono, P. W., Chen, S., Gilks, N., et al. (2000). Dynamic shuttling of TIA-1 accompanies the recruitment of mRNA to mammalian stress granules. J. Cell Biol. 151, 1257-1268. doi: 10.1083/jcb.151.6. 1257
Kedersha, N., Ivanov, P., and Anderson, P. (2013). Stress granules and cell signaling: more than just a passing phase? Trends Biochem. Sci. 38, 494-506. doi: 10.1016/j. tibs.2013.07.004

Kim, H. J., Kim, N. C., Wang, Y. D., Scarborough, E. A., Moore, J., Diaz, Z., et al. (2013). Mutations in prion-like domains in hnRNPA2B1 and hnRNPA1 cause multisystem proteinopathy and ALS. Nature 495, 467-473. doi: 10 1038/nature11922

Klucken, J., Shin, Y., Masliah, E., Hyman, B. T., and McLean, P. J. (2004). Hsp70 reduces $\alpha$-synuclein aggregation and toxicity. J. Biol. Chem. 279, 25497-25502. doi: 10.1074/jbc.m400255200

Koga, H., Martinez-Vicente, M., Arias, E., Kaushik, S., Sulzer, D., and Cuervo, A. M. (2011). Constitutive upregulation of chaperone-mediated autophagy in Huntington's disease. J. Neurosci. 31, 18492-18505. doi: 10.1523/JNEUROSCI. 3219-11.2011

Kong, S. M., Chan, B. K., Park, J. S., Hill, K. J., Aitken, J. B., Cottle, L., et al. (2014). Parkinson's disease-linked human PARK9/ATP13A2 maintains zinc homeostasis and promotes $\alpha$-Synuclein externalization via exosomes. Hum. Mol. Genet. 23, 2816-2833. doi: 10.1093/hmg/ddu099

Kowal, J., Tkach, M., and Théry, C. (2014). Biogenesis and secretion of exosomes. Curr. Opin. Cell Biol. 29, 116-125. doi: 10.1016/j.ceb.2014.05.004

Kumar, P., Pradhan, K., Karunya, R., Ambasta, R. K., and Querfurth, H. W. (2012). Cross-functional E3 ligases Parkin and C-terminus Hsp70-interacting protein in neurodegenerative disorders. J. Neurochem. 120, 350-370. doi: 10.1111/j.14714159.2011.07588.x

Kwon, I., Kato, M., Xiang, S., Wu, L., Theodoropoulos, P., Mirzaei, H., et al. (2013). Phosphorylation-regulated binding of RNA polymerase II to fibrous polymers of low-complexity domains. Cell 155, 1049-1060. doi: 10.1016/j.cell.2013. 10.033

Lawson, V. A., Lumicisi, B., Welton, J., Machalek, D., Gouramanis, K., Klemm, H. M., et al. (2010). Glycosaminoglycan sulphation affects the seeded misfolding of a mutant prion protein. PLoS One 5:e12351. doi: 10.1371/journal.pone. 0012351

Leonhardt, R. M., Vigneron, N., Hee, J. S., Graham, M., and Cresswell, P. (2013). Critical residues in the PMEL/Pmel17 N-terminus direct the hierarchical assembly of melanosomal fibrils. Mol. Biol. Cell 24, 964-981. doi: 10.1091/mbc. E12-10-0742

Li, X., Rayman, J. B., Kandel, E. R., and Derkatch, I. L. (2014). Functional role of Tial/Pub1 and Sup35 prion domains: directing protein synthesis machinery to the tubulin cytoskeleton. Mol. Cell 55, 305-318. doi: 10.1016/j.molcel.2014. 05.027

Liu, Q., and Dreyfuss, G. (1996). A novel nuclear structure containing the survival of motor neurons protein. EMBO J. 15, 3555-3565.

Liu-Yesucevitz, L., Bilgutay, A., Zhang, Y. J., Vanderweyde, T., Citro, A., Mehta, T., et al. (2010). Tar DNA binding protein-43 (TDP-43) associates with stress granules: analysis of cultured cells and pathological brain tissue. PLoS One 5:e13250. doi: 10.1371/journal.pone.0013250

Lotz, G. P., Legleiter, J., Aron, R., Mitchell, E. J., Huang, S. Y., Ng, C., et al. (2010). Hsp70 and Hsp40 functionally interact with soluble mutant huntingtin oligomers in a classic ATP-dependent reaction cycle. J. Biol. Chem. 285, 3818338193. doi: 10.1074/jbc.M110.160218

Luk, K. C., Kehm, V., Carroll, J., Zhang, B., O’Brien, P., Trojanowski, J. Q., et al. (2012). Pathological $\alpha$-synuclein transmission initiates Parkinson-like neurodegeneration in nontransgenic mice. Science 338, 949-953. doi: 10. $1126 /$ science. 1227157

Maji, S. K., Perrin, M. H., Sawaya, M. R., Jessberger, S., Vadodaria, K., Rissman, R. A., et al. (2009). Functional amyloids as natural storage of peptide hormones in pituitary secretory granules. Science 325, 328-332. doi: 10.1126/science. 1173155

McDonald, K. K., Aulas, A., Destroismaisons, L., Pickles, S., Beleac, E., Camu, W., et al. (2011). TAR DNA-binding protein 43 (TDP-43) regulates stress granule dynamics via differential regulation of G3BP and TIA-1. Hum. Mol. Genet. 20, 1400-1410. doi: 10.1093/hmg/ddr021

Morozova, O. A., March, Z. M., Robinson, A. S., and Colby, D. W. (2013). Conformational features of tau fibrils from Alzheimer's disease brain are faithfully propagated by unmodified recombinant protein. Biochemistry 52, 6960-6967. doi: 10.1021/bi400866w

Münch, C., O'Brien, J., and Bertolotti, A. (2011). Prion-like propagation of mutant superoxide dismutase-1 misfolding in neuronal cells. Proc. Natl. Acad. Sci. US A 108, 3548-3553. doi: 10.1073/pnas.1017275108 
Murphy, K. E., Cottle, L., Gysbers, A. M., Cooper, A. A., and Halliday, G. M. (2013). ATP13A2 (PARK9) protein levels are reduced in brain tissue of cases with Lewy bodies. Acta Neuropathol. Commun. 1:11. doi: 10.1186/2051-5960-1-11

Nomura, T., Watanabe, S., Kaneko, K., Yamanaka, K., Nukina, N., and Furukawa, Y. (2014). Intranuclear aggregation of mutant FUS/TLS as a molecular pathomechanism of amyotrophic lateral sclerosis. J. Biol. Chem. 289, 1192-1202. doi: 10.1074/jbc.M113.516492

Nonaka, T., Masuda-Suzukake, M., Arai, T., Hasegawa, Y., Akatsu, H., Obi, T., et al. (2013). Prion-like properties of pathological TDP-43 aggregates from diseased brains. Cell Rep. 4, 124-134. doi: 10.1016/j.celrep.2013.06.007

Olzscha, H., Schermann, S. M., Woerner, A. C., Pinkert, S., Hecht, M. H., Tartaglia, G. G., et al. (2011). Amyloid-like aggregates sequester numerous metastable proteins with essential cellular functions. Cell 144, 67-78. doi: 10.1016/j.cell. 2010.11.050

Pare, J. M., Tahbaz, N., López-Orozco, J., LaPointe, P., Lasko, P., and Hobman, T. C. (2009). Hsp90 regulates the function of argonaute 2 and its recruitment to stress granules and P-bodies. Mol. Biol. Cell 20, 3273-3284. doi: 10.1091/mbc.E09-010082

Parker, S. J., Meyerowitz, J., James, J. L., Liddell, J. R., Crouch, P. J., Kanninen, K. M., et al. (2012). Endogenous TDP-43 localized to stress granules can subsequently form protein aggregates. Neurochem. Int. 60, 415-424. doi: 10.1016/j.neuint. 2012.01.019

Pathak, D., Berthet, A., and Nakamura, K. (2013). Energy failure: does it contribute to neurodegeneration? Ann. Neurol. 74, 506-516. doi: 10.1002/ana.24014

Prusiner, S. B., McKinley, M. P., Bowman, K. A., Bolton, D. C., Bendheim, P. E., Groth, D. F., et al. (1983). Scrapie prions aggregate to form amyloid-like birefringent rods. Cell 35, 349-358. doi: 10.1016/0092-8674(83) 90168-x

Rajendran, L., Honsho, M., Zahn, T. R., Keller, P., Geiger, K. D., Verkade, P., et al. (2006). Alzheimer's disease beta-amyloid peptides are released in association with exosomes. Proc. Natl. Acad. Sci. U S A 103, 11172-11177. doi: 10.1073/pnas. 0603838103

Raposo, G., Tenza, D., Murphy, D. M., Berson, J. F., and Marks, M. S. (2001). Distinct protein sorting and localization to premelanosomes, melanosomes and lysosomes in pigmented melanocytic cells. J. Cell Biol. 152, 809-824. doi: 10. 1083/jcb.152.4.809

Raveendra, B. L., Siemer, A. B., Puthanveettil, S. V., Hendrickson, W. A., Kandel, E. R., and McDermott, A. E. (2013). Characterization of prion-like conformational changes of the neuronal isoform of Aplysia CPEB. Nat. Struct. Mol. Biol. 20, 495-501. doi: 10.1038/nsmb.2503

Ren, P. H., Lauckner, J. E., Kachirskaia, I., Heuser, J. E., Melki, R., and Kopito, R. R. (2009). Cytoplasmic penetration and persistent infection of mammalian cells by polyglutamine aggregates. Nat. Cell Biol. 11, 219-225. doi: 10.1038/ncb 1830

Rideout, H. J., Larsen, K. E., Sulzer, D., and Stefanis, L. (2001). Proteasomal inhibition leads to formation of ubiquitin/alpha-synuclein-immunoreactive inclusions in PC12 cells. J. Neurochem. 78, 899-908. doi: 10.1046/j.1471-4159. 2001.00474.x

Robertson, C., Booth, S. A., Beniac, D. R., Coulthart, M. B., Booth, T. F., and $\mathrm{McNicol}$, A. (2006). Cellular prion protein is released on exosomes from activated platelets. Blood 107, 3907-3911. doi: 10.1182/blood-2005-02-0802

Roodveldt, C., Bertoncini, C. W., Andersson, A., van der Goot, A. T., Hsu, S. T., Fernández-Montesinos, R., et al. (2009). Chaperone proteostasis in Parkinson's disease: stabilization of the Hsp70/alpha-synuclein complex by hip. EMBO J. 28, 3758-3770. doi: 10.1038/emboj.2009.298

Röthlein, C., Miettinen, M., Borwankar, T., Buerger, J., Mielke, T., Kumke, M. U., et al. (2014). Architecture of polyglutamine-containing fibrils from time resolved fluorescence decay. J. Biol. Chem. 289, 26817-26828. doi: 10.1074/jbc. M114.581991

Rykova, V. I., Leberfarb, E. Y., Stefanova, N. A., Shevelev, O. B., Dymshits, G. M., and Kolosova, N. G. (2011). Brain proteoglycans in postnatal development and during behavior decline in senescence-accelerated OXYS rats. Adv. Gerontol. 24, 234-243. doi: 10.1134/S2079057012010134

Saman, S., Kim, W., Raya, M., Visnick, Y., Miro, S., Saman, S., et al. (2012). Exosome-associated tau is secreted in tauopathy models and is selectively phosphorylated in cerebrospinal fluid in early Alzheimer disease. J. Biol. Chem. 287, 3842-3849. doi: 10.1074/jbc.M111.277061

Sanders, D. W., Kaufman, S. K., DeVos, S. L., Sharma, A. M., Mirbaha, H., Li, A., et al. (2014). Distinct tau prion strains propagate in cells and mice and define different tauopathies. Neuron 82, 1271-1288. doi: 10.1016/j.neuron.2014. 04.047

Sarkar, B., Mithu, V. S., Chandra, B., Mandal, A., Chandrakesan, M., Bhowmik, D., et al. (2014). Significant structural differences between transient amyloid- $\beta$ oligomers and less-toxic fibrils in regions known to harbor familial Alzheimer's mutations. Angew. Chem. Int. Ed Engl. 53, 6888-6892. doi: 10.1002/anie. 201402636

Savas, J. N., Ma, B., Deinhardt, K., Culver, B. P., Restituito, S., Wu, L., et al. (2010). A role for huntington disease protein in dendritic RNA granules. J. Biol. Chem. 285, 13142-13153. doi: 10.1074/jbc.M110.114561

Saxena, S., and Caroni, P. (2011). Selective neuronal vulnerability in neurodegenerative diseases: from stressor thresholds to degeneration. Neuron 71, 35-48. doi: 10.1016/j.neuron.2011.06.031

Scharf, J. M., Endrizzi, M. G., Wetter, A., Huang, S., Thompson, T. G., Zerres, K., et al. (1998). Identification of a candidate modifying gene for spinal muscular atrophy by comparative genomics. Nat. Genet. 20, 83-86. doi: 10.1038/1753

Schwartz, J. C., Ebmeier, C. C., Podell, E. R., Heimiller, J., Taatjes, D. J., and Chech, T. R. (2012). FUS binds the CTD of RNA polymerase II and regulates its phosphorylation at Ser2. Genes Dev. 26, 2690-2695. doi: 10.1101/gad. 204602.112

Schwartz, J. C., Wang, X., Podell, E. R., and Cech, T. R. (2013). RNA seeds higherorder assembly of FUS protein. Cell Rep. 5, 918-925. doi: 10.1016/j.celrep.2013. 11.017

Scotter, E. L., Vance, C., Nishimura, A. L., Lee, Y. B., Chen, H. J., Urwin, H., et al. (2014). Differential roles of the ubiquitin proteasome system and autophagy in the clearance of soluble and aggregated TDP-43 species. J. Cell Sci. 127, 12631278. doi: 10.1242/jcs. 140087

Shelkovnikova, T. A. (2013). Modelling FUSopathies: focus on protein aggregation. Biochem. Soc. Trans. 41, 1613-1617. doi: 10.1042/BST20130212

Shelkovnikova, T. A., Robinson, H. K., Southcombe, J. A., Ninkina, N., and Buchman, V. L. (2014). Multistep process of FUS aggregation in the cell cytoplasm involves RNA-dependent and RNA-independent mechanisms. Hum. Mol. Genet. 23, 5211-5226. doi: 10.1093/hmg/ddu243

Shu, Q., Crick, S. L., Pinkner, J. S., Ford, B., Hultgren, S. J., and Frieden, C. (2012). The E. coli CsgB nucleator of curli assembles to $\beta$-sheet oligomers that alter the CsgA fibrillization mechanism. Proc. Natl. Acad. Sci. U S A 109, 6502-6507. doi: 10.1073/pnas.1204161109

Si, K., Lindquist, S., and Kandel, E. R. (2003). A neuronal isoform of the aplysia CPEB has prion-like properties. Cell 115, 879-891. doi: 10.1016/s00928674(03)01020-1

Singh, N. N., Seo, J., Ottesen, E. W., Shishimorova, M., Bhattacharya, D., and Singh, R. N. (2011). TIAl prevents skipping of a critical exon associated with spinal muscular atrophy. Mol. Cell. Biol. 31, 935-954. doi: 10.1128/MCB.00945-10

Sipe, J. D., Benson, M. D., Buxbaum, J. N., Ikeda, S., Merlini, G., Saraiva, M. J., et al. (2014). Nomenclature 2014: amyloid fibril proteins and clinical classification of the amyloidosis. Amyloid 21, 221-224. doi: 10.3109/13506129.2014.964858

Snow, A. D., Mar, H., Nochlin, D., Kimata, K., Kato, M., Suzuki, S., et al. (1988). The presence of heparan sulfate proteoglycans in the neuritic plaques and congophilic angiopathy in Alzheimer's disease. Am. J. Pathol. 133, 456-463.

Snow, A. D., Wight, T. N., Nochlin, D., Koike, Y., Kimata, K., DeArmond, S. J., et al. (1990). Immunolocalization of heparan sulfate proteoglycans to the prion protein amyloid plaques of Gerstmann-Straussler syndrome, Creutzfeldt-Jakob disease and scrapie. Lab. Invest. 63, 601-611.

Sondheimer, N., and Lindquist, S. (2000). Rnq1: an epigenetic modifier of protein function in yeast. Mol. Cell 5, 163-172. doi: 10.1016/S1097-2765(00)80412-8

Spillantini, M. G., Tolnay, M., Love, S., and Goedert, M. (1999). Microtubuleassociated protein tau, heparan sulphate and alpha-synuclein in several neurodegenerative diseases with dementia. Acta Neuropathol. 97, 585-594. doi: 10.1007/s004010051034

Stöhr, J., Condello, C., Watts, J. C., Bloch, L., Oehler, A., Nick, M., et al. (2014). Distinct synthetic A $\beta$ prion strains producing different amyloid deposits in bigenic mice. Proc. Natl. Acad. Sci. U S A 111, 10329-10334. doi: 10.1073/pnas. 1408968111

Tanik, S. A., Schultheiss, C. E., Volpicelli-Daley, L. A., Brunden, K. R., and Lee, V. M. (2013). Lewy body-like $\alpha$-synuclein aggregates resist degradation and impair macroautophagy. J. Biol. Chem. 288, 15194-15210. doi: 10.1074/jbc. M113.457408

Tashiro, Y., Urushitani, M., Inoue, H., Koike, M., Uchiyama, Y., Komatsu, M., et al. (2012). Motor neuron-specific disruption of proteasomes, but not autophagy, 
replicates amyotrophic lateral sclerosis. J. Biol. Chem. 287, 42984-42994. doi: 10. 1074/jbc.M112.417600

Thellung, S., Villa, V., Corsaro, A., Pellistri, F., Venezia, V., Russo, C., et al. (2007). ERK1/2 and p38 MAP kinases control prion protein fragment 90-231-induced astrocyte proliferation and microglia activation. Glia 55, 1469-1485. doi: 10. 1002/glia.20559

Thomas, M. G., Loschi, M., Desbats, M. A., and Boccaccio, G. L. (2011). RNA granules: the good, the bad and the ugly. Cell. Signal. 23, 324-334. doi: 10.1016/j. cellsig.2010.08.011

Tomasi, V. (2010). Signal transduction in neurons: effects of cellular prion protein on fyn kinase and ERK1/2 kinase. Immun. Ageing 7(Suppl. 1):S5. doi: 10. 1186/1742-4933-7-S1-S5

Toombs, J. A., McCarty, B. R., and Ross, E. D. (2010). Compositional determinants of prion formation in yeast. Mol. Cell. Biol. 30, 319-332. doi: 10.1128/MCB. 01140-09

Tsai, N. P., and Wei, L. N. (2010). RhoA/ROCK1 signaling regulates stress granule formation and apoptosis. Cell. Signal. 22, 668-675. doi: 10.1016/j.cellsig.2009. 12.001

Tuite, M. F., and Cox, B. S. (2006). The [PSI+] prion of yeast: a problem of inheritance. Methods 39, 9-22. doi: 10.1016/j.ymeth.2006.04.001

Udan-Johns, M., Bengoechea, R., Bell, S., Shao, J., Diamond, M. I., True, H. L., et al. (2014). Prion-like nuclear aggregation of TDP-43 during heat shock is regulated by HSP40/70 chaperones. Hum. Mol. Genet. 23, 157-170. doi: 10. 1093/hmg/ddt408

Vanderweyde, T., Yu, H., Varnum, M., Liu-Yesucevitz, L., Citro, A., Ikezu, T., et al. (2012). Contrasting pathology of the stress granule proteins TIA-1 and G3BP in tauopathies. J. Neurosci. 32, 8270-8283. doi: 10.1523/JNEUROSCI.159212.2012

van Ham, T. J., Holmberg, M. A., van der Goot, A. T., Teuling, E., Garcia-Arencibia, M., Kim, H. E., et al. (2010). Identification of MOAG-4/SERF as a regulator of age-related proteotoxicity. Cell 142, 601-612. doi: 10.1016/j.cell.2010. 07.020

Vella, L. J., Greenwood, D. L., Cappai, R., Scheerlinck, J. P., and Hill, A. F. (2008). Enrichment of prion protein in exosomes derived from ovine cerebral spinal fluid. Vet. Immunol. Immunopathol. 124, 385-393. doi: 10.1016/j.vetimm.2008. 04.002

Vella, L. J., Sharples, R. A., Lawson, V. A., Masters, C. L., Cappai, R., and Hill, A. F. (2007). Packaging of prions into exosomes is associated with a novel pathway of PrP processing. J. Pathol. 211, 582-590. doi: 10.1002/path.2145

Vieira, T. C., Cordeiro, Y., Caughey, B., and Silva, J. L. (2014). Heparin binding confers prion stability and impairs its aggregation. FASEB J. 28, 2667-2676. doi: 10.1096/fj.13-246777

Virchow, R. (1855). Über den Gang der amyloiden degeneration. Virchows Archiv 8, 364-368. doi: 10.1007/BF01935311

Volpicelli-Daley, L. A., Luk, K. C., and Lee, V. M. (2014). Addition of exogenous $\alpha$-synuclein preformed fibrils to primary neuronal cultures to seed recruitment of endogenous $\alpha$-synuclein to Lewy body and Lewy neurite-like aggregates. Nat. Protoc. 9, 2135-2146. doi: 10.1038/nprot.2014.143

Wacker, J. L., Huang, S. Y., Steele, A. D., Aron, R., Lotz, G. P., Nguyen, Q., et al. (2009). Loss of Hsp70 exacerbates pathogenesis but not levels of fibrillar aggregates in a mouse model of Huntington's disease. J. Neurosci. 29, 9104-9114. doi: 10.1523/JNEUROSCI.2250-09.2009

Wacker, J. L., Zareie, M. H., Fong, H., Sarikaya, M., and Muchowski, P. J. (2004). Hsp70 and Hsp40 attenuate formation of spherical and annular polyglutamine oligomers by partitioning monomer. Nat. Struct. Mol. Biol. 11, 1215-1222. doi: $10.1038 / \mathrm{nsmb} 860$

Walsh, I., Seno, F., Tosatto, S. C., and Trovato, A. (2014). PASTA 2.0: an improved server for protein aggregation prediction. Nucleic Acids Res. 42, W301-W307. doi: 10.1093/nar/gku399

Wang, Y., Martinez-Vicente, M., Krüger, U., Kaushik, S., Wong, E., Mandelkow, E. M., et al. (2009). Tau fragmentation, aggregation and clearance: the dual role of lysosomal processing. Hum. Mol. Genet. 18, 4153-4170. doi: 10. 1093/hmg/ddp367

Watts, J. C., Condello, C., Stöhr, J., Oehler, A., Lee, J., DeArmond, S. J., et al. (2014). Serial propagation of distinct strains of $\mathrm{A} \beta$ prions from Alzheimer's disease patients. Proc. Natl. Acad. Sci. U S A 111, 10323-10328. doi: 10.1073/pnas. 1408900111

Waza, M., Adachi, H., Katsuno, M., Minamiyama, M., Sang, C., Tanaka, F., et al. (2005). 17-AAG, an Hsp90 inhibitor, ameliorates polyglutamine-mediated motor neuron degeneration. Nat. Med. 11, 1088-1095. doi: 10.1038/nm1298

Weber, S. C., and Brangwynne, C. P. (2012). Getting RNA and protein in phase. Cell 149, 1188-1191. doi: 10.1016/j.cell.2012.05.022

Wippich, F., Bodenmiller, B., Trajkovska, M. G., Wanka, S., Aebersold, R., and Pelkmans, L. (2013). Dual specificity kinase DYRK3 couples stress granule condensation/dissolution to mTORC1 signaling. Cell 152, 791-805. doi: 10. 1016/j.cell.2013.01.033

Xie, W., Li, X., Li, C., Zhu, W., Jankovic, J., and Le, W. (2010). Proteasome inhibition modeling nigral neuron degeneration in Parkinson's disease. J. Neurochem. 115, 188-199. doi: 10.1111/j.1471-4159.2010.06914.x

Xilouri, M., Brekk, O. R., Landeck, N., Pitychoutis, P. M., Papasilekas, T., Papadopoulou-Daifoti, Z., et al. (2013). Boosting chaperone-mediated autophagy in vivo mitigates $\alpha$-synuclein-induced neurodegeneration. Brain 136, 2130-2146. doi: 10.1093/brain/awt131

Xu, D., and Esko, J. D. (2014). Demystifying heparan sulfate-protein interactions. Annu. Rev. Biochem. 83, 129-157. doi: 10.1146/annurev-biochem-060713035314

Xu, G., Stevens, S. M. Jr., Moore, B. D., McClung, S., and Borchelt, D. R. (2013). Cytosolic proteins lose solubility as amyloid deposits in a transgenic mouse model of Alzheimer-type amyloidosis. Hum. Mol. Genet. 22, 2765-2774. doi: 10. 1093/hmg/ddt121

Yamazaki, T., Chen, S., Yu, Y., Yan, B., Haertlein, T. C., Carrasco, M. A., et al. (2012). FUS-SMN protein interactions link the motor neuron diseases ALS and SMA. Cell Rep. 2, 799-806. doi: 10.1016/j.celrep.2012.08.025

Yang, L., Gal, J., Chen, J., and Zhu, H. (2014). Self-assembled FUS binds active chromatin and regulates gene transcription. Proc. Natl. Acad. Sci. U S A 111, 17809-17814. doi: 10.1073/pnas.1414004111

Yuan, A. H., Garrity, S. J., Nako, E., and Hochschild, A. (2014). Prion propagation can occur in a prokaryote and requires the ClpB chaperone. Elife 3:e02949. doi: 10.7554/elife.02949

Zhang, Y. J., Gendron, T. F., Xu, Y. F., Ko, L. W., Yen, S. H., and Petrucelli, L. (2010). Phosphorylation regulates proteasomal-mediated degradation and solubility of TAR DNA binding protein-43 C-terminal fragments. Mol. Neurodegener. 5:33. doi: 10.1186/1750-1326-5-33

Zhao, X., and Yang, J. (2010). Amyloid- $\beta$ peptide is a substrate of the human $20 \mathrm{~S}$ proteasome. ACS Chem. Neurosci. 1, 655-660. doi: 10.1021/cn100067e

Conflict of Interest Statement: The authors declare that the research was conducted in the absence of any commercial or financial relationships that could be construed as a potential conflict of interest.

Received: 09 September 2014; accepted: 30 January 2015; published online: 18 February 2015.

Citation: Falsone A and Falsone SF (2015) Legal but lethal: functional protein aggregation at the verge of toxicity. Front. Cell. Neurosci. 9:45. doi: 10.3389/fncel. 2015.00045

This article was submitted to the journal Frontiers in Cellular Neuroscience. Copyright (C) 2015 Falsone and Falsone. This is an open-access article distributed under the terms of the Creative Commons Attribution License (CC BY). The use, distribution and reproduction in other forums is permitted, provided the original author(s) or licensor are credited and that the original publication in this journal is cited, in accordance with accepted academic practice. No use, distribution or reproduction is permitted which does not comply with these terms. 